\title{
Cell-Biomaterial Interaction: Strategies To Mimic The Extracellular Matrix
}

\author{
Edorta Santos, Gorka Orive, Rosa M Hernández and Jose Luis Pedraz \\ University of the Basque Country (UPV-EHU)/NanoBioCel Group, CIBER BBN
}

Spain

\section{Introduction}

Culturing cells out of their natural niches requires a comprehensive insight into the biochemical and biophysical rules that dictate cell biology. The cell is not an individual entity, but it is part of a complex and dynamic architecture formed by itself, insoluble macromolecules of the extracellular matrix (ECM), soluble morphogens and growth factors, and surrounding cells (Tibbitt and Anseth, 2009). This relation is orchestrated by spatiotemporal signalling patterns, where cells receive and process information from the ECM at the same time that they remodel it. Thus, cells and their microenvironment are linked by a dynamic and bidirectional interaction which governs the whole tissue and the organ physiology (Sands and Mooney, 2007).

Nowadays, an important goal for tissue engineering is to recreate the most critical aspects of such a complex scenario, so that processes regulating cell fate as well as cell function can be understood and controlled. Nonetheless, the complexity presented by the interactions given between natural ECM and cells, together with our poor understanding of the signal pathways that drive cell biology, make more than challenging designing appropriate models for the study. In this sense, the technology of biomaterials offers the exciting chance of deconstructing this landscape up to the point of analyzing the effect of isolated components of ECM on the hosted cells (Lutolf et al, 2009b). In fact, microfabrication, and more recently nanofabrication (Dvir et al, 2011) are allowing the creation of suitable models where key factors may be studied from the nanometer to the supramillimeter length scale (Sands and Mooney, 2007, Wong Po Foo et al, 2006, Huang et al, 2006).

Traditionally, cellular scaffolds from the typical 2D polystyrene surfaces to the first $3 \mathrm{D}$ constructs (natural or artificial) were intended as inert platforms that merely served as support for the cultured cells. Since then, more emphasis was given to provide these matrices with suitable physical (e.g. stiffness and mass transfer) and chemical (e.g. employed material type and degradation rate) properties for tissue engineering and cell transplantation (Langer and Vacanti, 1993, Freed et al, 2006). More recently, the biology of the scaffolds is gaining the attention of scientists, including signals that cells receive via adhesion to the material or directly from soluble factors in the microenvironment (Lutolf and Hubbell, 2005, Kong and Mooney, 2007, Place et al, 2009).

Interestingly, the inspiration that guide the design of new biomaterial approaches is always drawn from the observation on various length scales of the materials arranged naturally by the cells in the tissues (Huebsch and Mooney, 2009). Thus, gaining insight into so far 
unknown questions motivates the design of new models that allow for investigating more thoroughly the cell-ECM interaction and its effects in a feedback manner. In this book chapter, we discuss the different strategies that are being carried out by scientists worldwide from the simplest to the more complex ones, specially focusing on the biomaterials and techniques used for that aim.

\section{Native extracellular matrix (ECM)}

The natural ECM is a highly hydrated, hierarchically organized, heterogeneous, self assembled, bioactive and dynamic structure that regulates vital cellular functions such as adhesion, migration, proliferation, differentiation, morphogenesis and gene expresion (Tsang et al, 2010). It is demonstrated that hosted cells are able to sense and interpret the information coming from the ECM responding and reorganizing in function of topography (Bauer et al, 2009), mechanical properties (e.g. stiffness, viscosity and elascticity) (Huebsch et al, 2010, Levental et al, 2009), molecules presented by the ECM (Rozario and DeSimone, 2010) and concentration gradients of both soluble and tethered growth factors (Cohen et al, 2009). Thus, cells receive and process a multiple combination of physicochemical and biological cues always within a spatio-temporal context and in three main ways: cell-cell contacts, cell-ECM interactions and cell-soluble/tethered factor interactions (Fisher et al, 2010) (Figure 1).

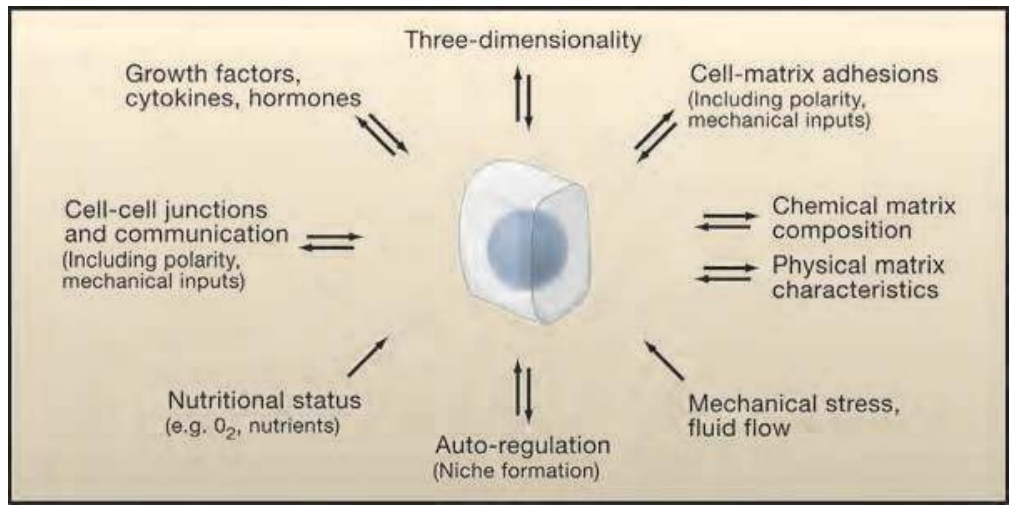

Fig. 1. Cell biology is goberned by a complex series of interactions with the ECM.

Reprinted from (Yamada and Cukierman, 2007), copyright 2007, with permission from Elsevier.

Mechanical properties from ECM are given by a complex structure of interwoven fibrous proteins of collagen and elastin ranging diameters from 10 to various hundreds of nanometers. Other insoluble proteins such as fibronectin and laminin are deposited on this backbone providing specific binding moieties which cells recognize via integrins on their cell surface. These bonds make possible for the cells to sense the architecture and physical features of its microenvironment which have been shown to play critical roles in cell shape, migration, proliferation and differentiation (Hynes, 2009). Highly hydrated glycosaminoglycans such as hyaluronic acid and heparan sulphate fill the remaining space of this fibrous mesh serving as compression stress buffer and sequestering growth factors 
(Sasisekharan et al, 2002). Cells take part actively in the remodelling of this dynamic structure, as they degrade the ECM by means of matrix-metalloproteinase (MMP) secretion at the same time they deposit their own ECM components. Both processes are regulated by integrin-mediated signalling pathways (Daley et al, 2008) and are absolutely necessary in order to allow cell function and maintain a correct tissue homeostasis.

ECM composition varies considerably from tissue to tissue and changes during disease and aging. However, a global understanding of its main structural components as well as the basic dynamics that govern these processes is essential in order to build 3D culture models and progress in tissue regeneration field.

\section{Simple 2D models}

Deconstructing 3D extremely complex scenarios into 2D simple models is a smart way to perform univariable experiments by which parse out the effect of isolated factors - either natural or synthetic - in cells. Furthermore, it is a powerful tool to make infinite combinations of structural, biophysical and biochemical parameters and thus elucidate some of the mechanisms that dictate cell biology. Other advantages of bidimensional models include the facility to exert a precise control over chemical and topographical properties even at nanometer scale, the overall straightforward processing and the possibility to harvest the cells effortlessly.

\subsection{Chemical variables}

The first step in our attempt to recapitulate the ECM should be the identification of those molecules that play a principal role in the regulation of the specific cellular functions. In this context, many authors have carried out ECM microenvironment arrays to asses the effect of different concentration and presentation patterns of soluble and anchored molecules individually and combined (Flaim et al, 2005, LaBarge et al, 2009, Brafman et al, 2009). A good example of this has been recently described. In fact, by using a microarray technology hundreds of spots recreating unique ECM signaling microenvironments were printed with a robotic spotter onto acrylamide hydrogels in order to identify factors that affect the function of hepatic stellate cells (HSCs) (Brafman et al, 2009).

Chemical signals within the ECM act via different mechanisms including receptor ligands associated cell-cell interactions, molecules tethered to the glycosaminoglycans, and soluble factors (autocrine and paracrine signalling, hormones, etc.). Studying the effects of a defined concentration of a soluble growth factor over time is usually hampered by other signals that cells secrete to the microenvironment. Compared to traditional culture methods, microfluidic devices offer the possibility to hold a greater control over cell microenvironment. Using these techniques, factors secreted by cells are continuously washed away, at the same time that microenvironment is replaced with known concentrations of desired growth factors, thus minimizing autocrine and paracrine signaling effects (Discher et al, 2009, Chung et al, 2005).

Cell-cell interactions are often explored culturing two cell types in combination. Nevertheless, since intracellular signalling pathways are complex and are related with eachother, by simply co-culturing cells is difficult to separate the real effect of the aimed molecule from the background generated by all the other ligands presented by nearby cells. Given that these molecules are immobilized in the plasmatic membrane, a simple solution to address this issue is basically presenting desired ligands covalently coupled or associated 
via secondary bounding to the surfaces of our 2D models (Lutolf et al, 2009b, Irvine et al, 2002). An example of this is the work by Suzuki et al., who proved how tethered DLL1 (a ligand of NOTCH1 receptor) resulted more effective than its soluble form increasing the number of $\mathrm{CD}_{133^{+}}$human cord-blood cells that were able to reconstitute the circulation of irradiated mice (Lutolf et al, 2009b, Suzuki et al, 2006).

The exposition of molecules that are naturally bound to glycosaminoglycans in the ECM (e.g. VEGF) can be simulated in the same way. Notably, soluble morphogens may also show better biological activity when they are immobilized, probably due to improved protein stability and persistent signalling triggering (Fan et al, 2007). In this sense, Alberti et al. demonstrated the relevance of ligand presentation mode in guiding cell fate during development, maintaining the pluripotency of mouse ESC for at least 2 weeks by means of immobilized leukaemia inhibitory factor (LIF) (Lutolf et al, 2009b, Alberti et al, 2008).

On the other hand, probing individual or few molecules per assay may be useful and constructive, but the search of unknown variables and novel synthetic materials that may regulate cell behavior requires combinatorial and high-throughput screening (CTHS) approaches, which make possible processing elevated number of samples at the clonal level in arrays of nanolitre-scale (Lutolf et al, 2009b, Fisher et al, 2010). CTHS is usually employed to test the bioactivity of a great variety of soluble growth factors, ECM molecules and materials (Peters et al, 2009). For instance, Langer and colleagues have performed this technique to discover polymers that are able to promote cell adhesion and proliferation both in mesenchymal stem cells (MSC) and embryonic stem cells (ESC) (Anderson et al, 2004, Mei et al, 2009), and more recently, they reported the same procedure to examine attachment and insulin expression of islet cells in 496 different polymers (Mei et al, 2010).

\subsection{Physical variables}

For the past few decades, chemical composition of the biomaterials has been the main concern in the design of different strategies. However, now there is a growing interest among tissue engineers in exploring their physical properties, including topography and mechanics (e.g. stiffness), which have been demonstrated to play a key role in the cellular decision making (Huebsch and Mooney, 2009).

\subsubsection{Topography}

In vivo, the architecture of the ECM on the nanometer scale provides additional information to the cells which have to adapt to many topographical features imposed by their immediately surrounding area. The fiber diameter or the presence of folded proteins may regulate cell interactions through a phenomenon known as contact guidance (Dvir et al, 2011). A good strategy to study this effect has been described using different well defined nanopatterned geometries called nanograting, nanopost and nanopit arrays, which aim to reproduce the structure of native ECM from $5 \mathrm{~nm}$ to micrometer scale (Bettinger et al, 2009) (Figure 2A). In the mentioned work authors reported, for example, how vastly ordered topographies neither supported observable cell adhesion nor osteoblastic differentiation in MSCs, whereas those surfaces that simulated topographical disorder promoted bone mineral production (Dvir et al, 2011, Bettinger et al, 2009).

Although the precise mechanism that governs the morphological response is still under debate, it seems that the large body of current theories point toward a possible generation of anisotropic stresses as the main responsible (Figure 2B). 
In other respects, there exist many other features of the ECM that condition cell geometry, and thus, cell fate. Among them, distribution of the binding moieties is a remarkable one and deserves special attention, so that this topic will be discussed apart in the following section.

A

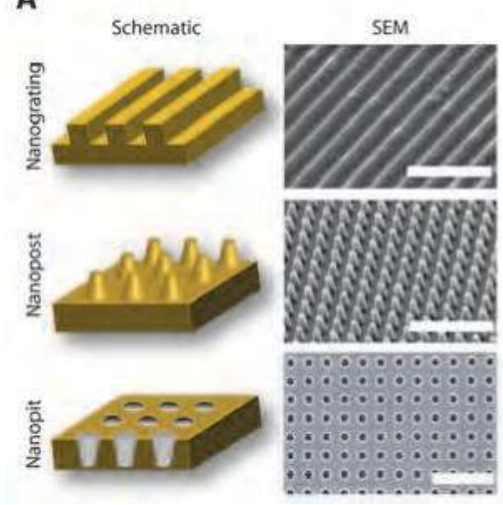

B
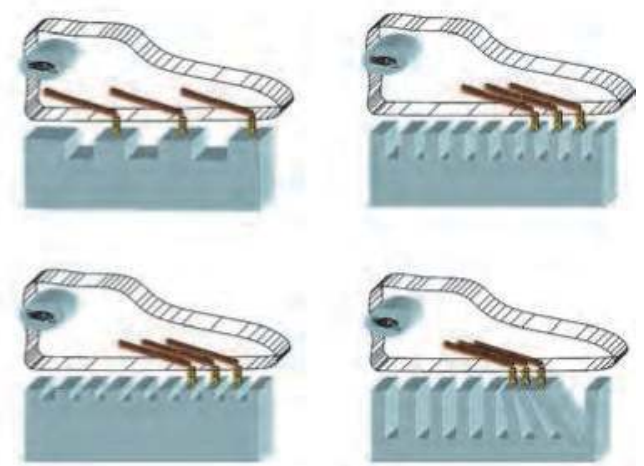

Fig. 2. (A) Schematic representation and their corresponding SEM images of nanograting (scale bar $5 \mu \mathrm{m}$ ), nanopost array (scale bar $5 \mu \mathrm{m}$ ) and nanopit array (scale bar $1 \mu \mathrm{m}$ ). Reproduced with permission from (Bettinger et al, 2009). Copyright Wiley-VCH Verlag $\mathrm{GmbH} \&$ Co. KGaA. (B) Schematic illustration displaying different cytoskeleton rearrangements occurring due to different substrate topographies.

\subsubsection{Adhesion ligand patterns}

One of the most relevant ways to establish cell-ECM interaction is mediated through integrin-mediated adhesions, which they use to connect cell cytoskeleton to adhesion molecules, such as fibronectin or laminin, sited on the fibers (Heino and Kapyla, 2009). This phenomenon is known as focal adhesion (FA), which constitute specific types of large macromolecular assemblies through which both mechanical force and regulatory signals are transmitted. Focal adhesions serve to guide the cell through the ECM, as these linkages induce the arrangement and polarization of cell cytoskeleton. Furthermore, FA is absolutely necessary to prevent anoikis in anchorage dependent cells (Mooney and Vandenburgh, 2008).

Cells may be provided with adhesion surfaces by using a variety of naturally derived ECM molecules such as collagen or fibrin, or using these molecules to decorate synthetic polymers to which adhesion is regulated by adsorbed proteins. However, protein engineering has evolved such, that we are able to distinguish functional domains within large ECM molecules and incorporate them into otherwise inert substrates. Thus, epitopes that mediate cell-adhesion can be mimicked using synthetic peptides. Among them, perhaps the most known ones are arginine-glycine-aspartic acid (RGD), derived from fibronectin, and tyrosine-isoleucine-glycine-serine-arginine (YIGSR), derived from laminin.

It has been seen that not only the adhesion moieties themselves, but also their density and spatial distribution on micrometer and nanometer scales influence cell fate (Silva et al, 2004). Manipulating the way adhesion moieties are presented to the cells, it is possible to induce major cellular processes such as migration, proliferation and differentiation (Mooney and Vandenburgh, 2008). With this idea, nanoscale patterns of RGD islands in hydrogels have 
been varied without altering the final ligand density. For instance, hydrogels with reduced island spacing were produced by uniformly distributing alginate chains containing a single ligand, while more increased island spacing was achieved by mixing unmodified chains and chains coupled with multiple peptides (Lee et al, 2004) (Figure 3). Thus, more closely spaced island favored cell spreading, while more widely spaced islands supported differentiation (Comisar et al, 2007). Besides, other groups with the same goal have followed strategies alike. Once again, RGD was presented by covering an inert surface with polyethylene oxide (PEO) tethers carrying single RGD moieties (uniform patterns), or mixing tethers conjugated with multiple ligands and unmodified tethers (clustered patterns) (Maheshwari et al, 2000).
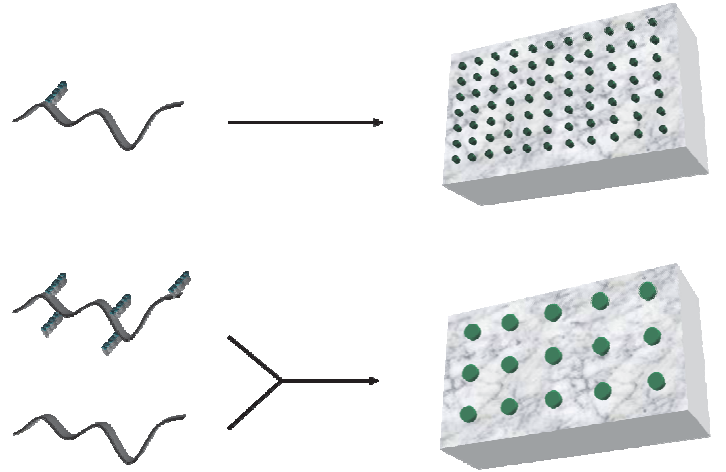

Fig. 3. Strategies to achieve well-characterized nanoscale patterns of RGD islands.

Within the natural niche, connective tissue cells exhibit great differences in morphology. In the same way differentiation causes changes in cells shape, it has long been appreciated that cell shape alone also may be responsible of cell commitment (Chen et al, 1997, Watt et al, 1988). In this respect, it was reported that using photolithography and microcontact printing techniques (Tan et al, 2002) single MSCs were seeded onto fibronecting islands of different sizes, thus allowing different degrees of cell spreading. Strikingly, even when a mixture of induction factors was added to medium, cells placed on small islands (round morphology) expressed adipogenic markers, whereas those spread on islands of greater area differentiated into osteogenic lineage (McBeath et al, 2004).

\subsubsection{Mechanical properties}

In addition to responses given by chemical signals, mechanical properties of biomaterials can also influence cell behavior and lineage differentiation. Even if the precise mechanisms responsible of such processes are still poorly understood, it seems to be a consensus about the hypothesis that mechanosensing is an active cellular process that entails a dynamic and reciprocal interaction between the ECM and the motor proteins that are connected to the cytoskeleton (Huebsch and Mooney, 2009). Hence, cells do not only exert forces, but also, respond to the resistance sensed through cytoskeleton organization/tension triggering a series of intracellular signaling pathways, which at the same time activate or inhibit gene expression (Discher et al, 2005, Guilak et al, 2009). In this context, the ability to recapitulate different grades of matrix rigidity by means of elastic substrates of controlled stiffness is making possible to study the traction forces exerted by cells and to establish correlations with triggered effects. 
Typically, the easiest way to manipulate the mechanical properties in 2D hydrogel substrates has been using different concentrations of polymer and/or cross-linking agent or varying the polymer properties (e.g. molecular weight or monomer ratio). For example, by altering the percentage of PEG polymer in the pre-gelled solution it is possible to obtain different range of rigidities, which may affect cell behavior. In fact, authors demonstrated that a elastic modulus of $12 \mathrm{kPa}$ favored muscle stem cell (MuSC) self-renewal in vitro (Gilbert et al, 2010). Similarly, for collagen-coated polyacrylamide gels, simply adjusting the bis-acrylamide cross-linker allows variations in final stiffness. Following this strategy, it has been observed in a fantastic study how MSCs plated on soft matrices that resembled brain tissue showed upregulation of neuronal markers, while those plated on matrices that resembled muscle and collagenous bone expressed myogenic and osteogenic markers respectively (Engler et al, 2006) (Figure 4). Lastly, by employing alginates of different monomeric ratios (mannuronic/guluronic acid ratio) it is reported that it is possible to control myoblast phenotype (Rowley and Mooney, 2002).

All these strategies are useful, but they require the preparation of a single formulation to resemble each modulus, and moreover, once the gel if formed the properties are fixed. More sophisticated techniques are allowing the creation of elasticity gradients, even in situ, to screen the effect of a wide range of moduli on cells. Thus, in polyacrylamide-based photodegradable gels, the modulus can be decreased $20-30 \%$ with light irradiation in the presence of cells (Frey and Wang, 2009). Similarly, Anseth and co-workers have developed a dynamic system of PEG-based hydrogels that gelled through a photodegradable cross-linker (Kloxin et al, 2010a). This dynamic system is able to de-activate the valvular interstitial cell (VIC) differentiation upon is situ creation of stiffness gradient.

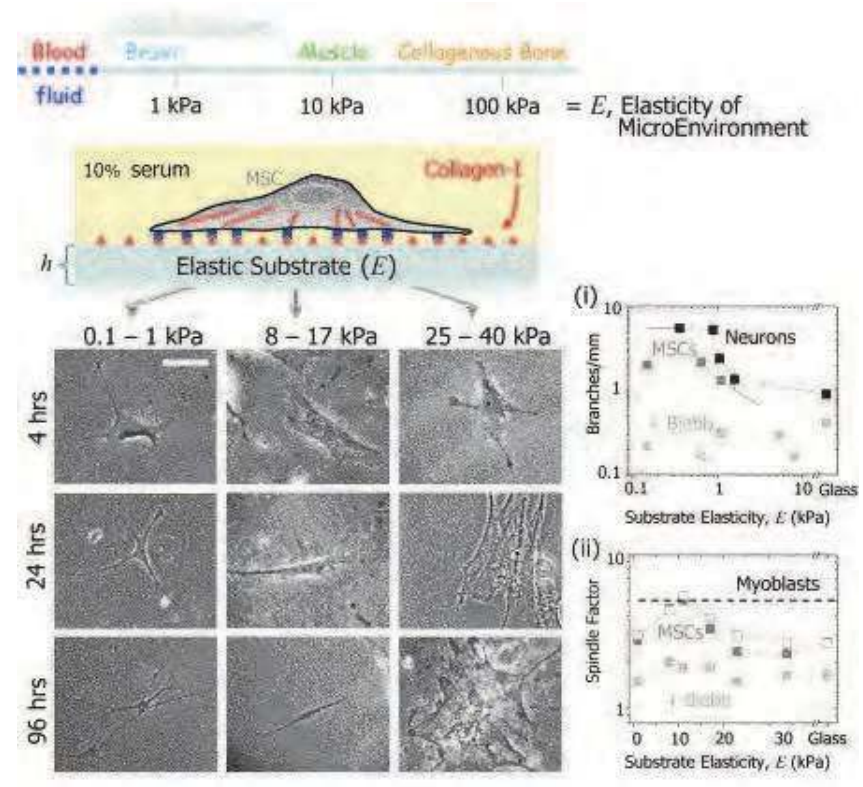

Fig. 4. Substrate elastic modulus determines differentiation of MSCs to different cell-linages. Reprinted from (Engler et al, 2006), copyright 2006, with permission from Elsevier. 
Two-dimensional cell cultures have revealed a great amount of information regarding the mechanical activity of cells in both physiological and disease-related situations, including cell migration, tissue homeostasis and tumor growth (Gardel and Schwarz, 2010). For example, it has been reported that in acrylamide hydrogels cast with elasticity gradients cells tended to invade stiffer areas guided by a process known as "durotaxis" (Discher et al, 2009, Lo et al, 2000, Isenberg et al, 2009). As stated by cited authors, such phenomenon may contribute to shed light on the mechanism promoting MSC homing to injured zones (Pittenger and Martin, 2004), since fibrotic tissues formed as a result of processes like acute myocardial infarction have shown a noticeable increase in the elastic modulus (Discher et al, 2009, Berry et al, 2006).

\subsection{Combining chemical and physical variables}

Many of the physiological processes that occur in vivo can be reconstructed and recreated by simple 2D models, thus avoiding unnecessary background "noise" that is often presented in complex scenarios. In this sense, high-throughput assays that permit elucidating how physical and chemical variables affect the cellular function in a simultaneous and independent way may result very advantageous. For instance, polymers like PEG, which are optimum to create non-fouling highly tuneable substrates, can be very useful to perform microwell arrays by which the combinatorial effects of a known elastic modulus (e.g. typical of bone marrow) and different ECM molecules indirectly tethered by microcontact printing can be explored (Lutolf et al, 2009b, Lutolf et al, 2009a). Thus, 2D cultures will probably continue being suitable candidate models to collect great amount of information and transfer it into more and more complex equations. Nonetheless, 2D assays should always be considered as preliminary screening assays which must be confirmed in 3D platforms first, and then in vivo.
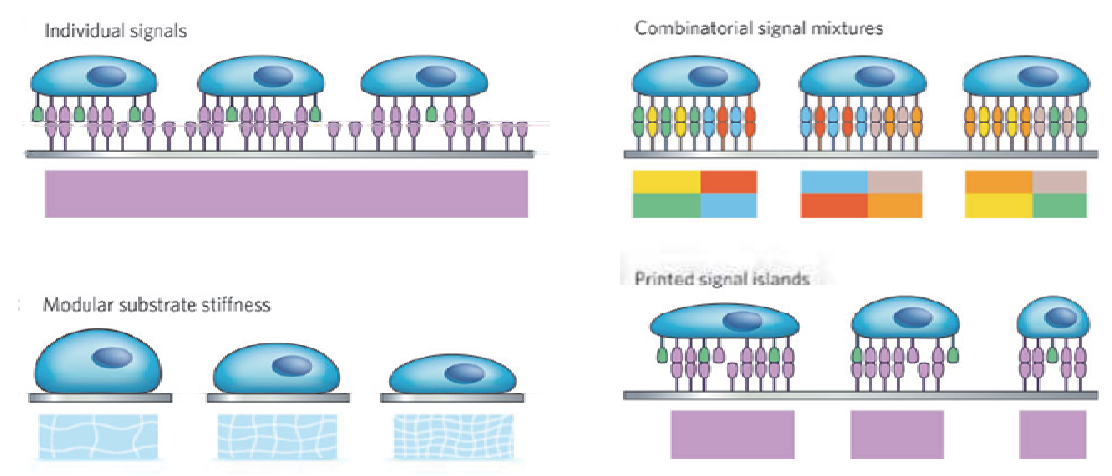

Fig. 5. Schematic summary of 2D engineered models to recapitulate some of the cell-ECM interactions. Reprinted and adapted by permission from Macmillan Publishers Ltd: Nature (Lutolf et al, 2009b), copyright 2009. http:/ / www.nature.com

\section{The leap to 3D models}

As described above, 2D approaches have given rise to exciting results, many of which have been pivotal in the understanding of cell-ECM interaction. However, recent findings suggest 
that cells often show a non-natural behavior when they are moving away from their natural niches and seeded onto flat substrates (Tibbitt and Anseth, 2009). Only to mention some examples, breast epithelial cells exhibited a tumoral trend when assayed in 2D, while regressed to normal state upon transferal to 3D models resembling their natural niche (Tibbitt and Anseth, 2009, Petersen et al, 1992). In the same way, increased chondrogenesis have been noticed in ESCs cultured as 3D embryoid bodies when compared to the monolayer conformation (Tibbitt and Anseth, 2009, Tanaka et al, 2004). Therefore, while 2D experiments represent a versatile and accurate way to screen the effects of isolated compounds of the ECM on cells, 3D experiments are designed to direct a progressive and steady reconstruction of the complexity that entails the native ECM.

The disparities in cellular function described between 2D and 3D approaches are mainly given by the manner in which cells perceive their surrounding microenvironment. Cells plated onto 2D substrates are polarized, maintaining only part of their surface anchored and exposing remaining parts to the culture media. Moreover, the contact with neighboring cells is also limited to the flat edges that share each-others. This is in sharp contrast with the natural environment of the tissues, where each cell closely interacts with the nearby cells and the ECM (Gelain et al, 2007). Hence, 3D environment-based interplay reflects a more distributed integrin usage and enhanced biological activity (Cukierman et al, 2001). Mass transport physics is also absolutely altered. Growth factors, morphogens, cytokines and so forth quickly diffuse in the media of 2D cultures, reaching cells uniformly, whereas native ECM produces chemical and biological diffusion gradients that play a key role in signaling and tissue development (Ashe and Briscoe, 2006). As seen before, cell shape also has its influence on cell commitment. Once again, cells on 2D cultures are limited to a planar and spread morphology and do not experience the more complex morphologies found in vivo (Tibbitt and Anseth, 2009). Furthermore, 2D surfaces offer almost undetectable resistance to cell migration, which contrasts notably with the mechanical interactions that must be given in vivo for such aim.

Therefore, the design of 3D models that resemble with more or less accuracy the native ECM becomes crucial in order to obtain reliable results that approximate to reality. Nonetheless, mimicking the ECM by our own means is not simple, especially because there is much we do not know yet about the cell-ECM cross-talk that occurs in vivo. As a consequence, the most frequently used models so far have been hydrogel scaffolds formed by animal ECMderived proteins, Matrigel ${ }^{\circledR}$ or Vitrogen ${ }^{\circledR}$ among others (Lutolf, 2009b). Even if these biosystems have provided seminal understanding for cell biology field in the past few decades, they are far from being ideal. Among the main limitations we can find a reduced flexibility to modulate their biophysical and biochemical properties (and furthermore, to control such variables independently), immunogenity, batch-to-batch variability and illdefined complexity that leads to little mechanistic information (Fisher et al, 2010, Lutolf, 2009b).

Assuming some of these limitations, hydrogels formed by synthetic polymers, and naturally derived polymers including alginate, agarose, chitosan etc. have become the biomaterial of choice for artificial ECM reconstruction. Hydrogels are able to resemble the nature of most tissues due to their high water content, the presence of pores that allow for the free diffusion of oxygen, nutrients and growth factors, morphogens, etc. (Tibbitt and Anseth, 2009). Most importantly, many hydrogels offer the possibility to encapsulate cells under gentle and cytocompatible conditions, and furthermore, their physicochemical properties can be easily tuned (Orive et al, 2009). 


\subsection{Mass-transport and pore size}

One of the first points that concerns scientists when it comes to leap to 3D is not only the fact that cells may suffer the lack of gases and nutrients, but also how they are going to face the physical constrains that hamper cell proliferation, migration and morphogenesis. In general, pore sizes of less than $1 \mu \mathrm{m}$ are able to support free diffusion of molecules, but not cellular migration, whereas pores in the range of $\approx 10-100 \mu \mathrm{m}$ readily allow host cells to migrate through the entire volume of the scaffold (Riddle and Mooney, 2004). Most chemically crosslinked polymer hydrogels form mesh-like structures with pores on the order of tens of nanometers, which means that they are small enough even to prevent cellular events such as filopodia (Lutolf, 2009b). Thus, cells remain literally trapped within their microvoids, showing round morphology.

Bioengineers have managed to increase polymer porosities in different manners, some of which are exemplified below. Assembling a PEG hydrogel in the presence of crystal colloidal templates that could be further removed by solvent extraction ("leaching") provides scaffolds with a pore range of 20-60 $\mu \mathrm{m}$ (Stachowiak et al, 2005). Another alternative approach is the use of $\mathrm{CO}_{2}$ as porogen in the production of PEG scaffolds with interconnected pores ranging in size from 100 to $600 \mu \mathrm{m}$, which were used to promote osteogenesis in MSCs (Keskar et al, 2009). Similarly, it has been demonstrated the potential of two-photon initiation to direct the patternalized polymerization of multifunctional acrylate monomers. With this technique uniform 12 to $110 \mu \mathrm{m}$ pore size range were achieved to further study cell migration on basis of pore size (Tayalia et al, 2008). A more recent work showed that permeability can be easily improved in PEG hydrogels incorporating hydrophobic nanoparticles that induced partially looser cross-linking density. In fact, a recent study showed that viability and functionality of encapsulated cells was improved without altering scaffold mechanical properties (Lee et al, 2010).

On the other side, since the typical cell size $(\approx 7-15 \mu \mathrm{m})$ is similar to or smaller than the described microstructures, some authors defend that the range of microporosities $(\approx 10-100$ $\mu \mathrm{m}$ ) will effectively act as 2D surfaces with curvature for cell attachment (Tibbitt and Anseth, 2009, Gelain et al, 2007). One possibility to address this problem is the fabrication of nanofibilar architectures. In this sense, electrospinning (Ayres et al, 2010) and molecular self-assembly (Zhang, 2003) are increasingly growing nanofabrication techniques that enable the production of 3D scaffolds formed by interwoven fibers that resemble the natural collagen structures of the native ECM (Dvir et al, 2011). Nevertheless, as they are somewhat different to the hydrogels discussed so far, these procedures will be described apart (see 5.7 section).

\subsection{Presentation of adhesive moieties}

ECM-derived and inherently adhesive materials like collagen or Matrigel ${ }^{\circledR}$ do not result very effective to study the impact of cell-adhesion on cellular function. Therefore, as in 2D models, 3D inert scaffolds can be also modified with adhesion sequences. For PEG hydrogels, this can be easily achieved by novel polymerization mechanisms such as thiolene (Khire et al, 2006) and thiol-acrylate chemistries (Salinas and Anseth, 2008), while other polymers like alginate are usually modified by means of carbodiimide chemistry (Rowley et al, 1999).

Over the last few years, the impact of ligand density within the scaffolds and how its availability affects cell behavior have been deeply studied. For example, fluoresce resonance energy transfer-based technique (FRET) was used to observe that pre-osteoblasts and 
myoblasts encapsulated within alginate hydrogels conjugated with different RGD densities proliferated and differentiated on basis of the number of bonds they employed to attach the matrix (Kong et al, 2006). Likewise, isolating the effects of ligand island spacing from ligand density can be facilely performed by mixing alginate chains coupled with multiple moieties and unmodified chains (notorious island spacing), or mixing single ligand conjugated chains together (proximal island spacing). Thus, it was seen that in preosteoblasts and D1 stem cells bond number increased together with ligand density but, on the contrary, was not affected by island spacing (Hsiong et al, 2008).

On the other hand, much attention has been paid to the patterning of adhesive moieties. In this regard, Shoichet and co-workers described a couple of studies in which after using both agarose (Luo and Shoichet, 2004) and HA (Musoke-Zawedde and Shoichet, 2006), cells seeded on the top of the gels invaded and migrated within the scaffolds through vertical RGD channels patterned with a beam of ultraviolet light. Finally, the same group was able to gain resolution in the patterning of the scaffolds using multi photon laser, with which they immobilized biomolecules in micropatterned volumes within agarose gels (Wosnick and Shoichet, 2008) (Figure 6). In all cases, agarose or hyaluronan were covalently modified with a derivative of cysteine protected with a photocleavable group. Thus, upon laser beam exposition protecting groups were removed and desired oligopeptides could be covalently immobilized in patterned sites via Michael-type addition (micrometric resolution). In parallel with these works, West's group employed a technique called two-photon laser scanning (TPLS) photolithography in PEG diacrylate (PEGDA) hydrogels, where encapsulated dermal fibroblasts were able to migrate guided by precisely patterned RGD moieties (Lee et al, 2008).

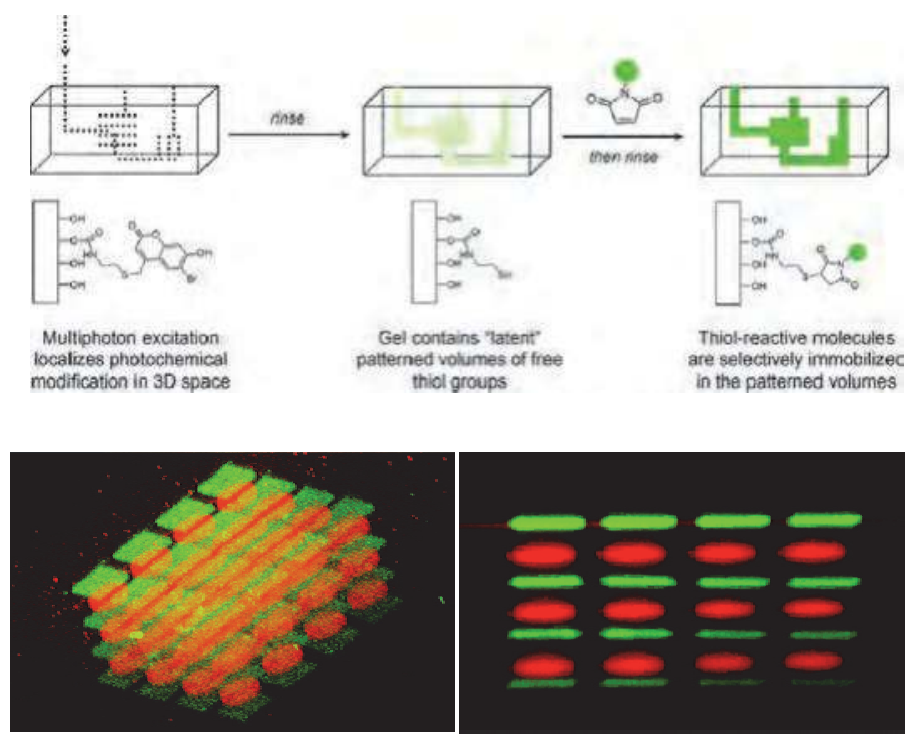

Fig. 6. Schematized multiphoton chemical patterning in hydrogels and resulting oblique and side views of fluorescence images taken from 3D patterned squares and circle arrays (50 $\mu \mathrm{m}$ diameter). Reprinted and adapted with permission from (Wosnick and Shoichet, 2008).

Copyright 2008 American Chemical Society. 
Nevertheless, there are also appealing models that can be carried out using ECM derived hydrogels. Thus, culturing MSCs within micropatterned collagen volumes of a determined shape that were immersed within agarose scaffolds, was useful to note that in the presence of pro-osteogenic and pro-adipogenic factors mixture, MSCs located at the edge of multicellular islands differentiated into osteogenic linage, while those in the center became adipocytes (Ruiz and Chen, 2008). Such approach revealed the importance of geometric forces in cell commitment.

\subsection{Mechanical properties}

Scaffold mechanical properties impact drastically on cell biology. The ability to modulate such features in 3D models has also been of a great interest. Researchers have developed different strategies to manipulate the elastic modulus of their scaffolds so that desired original tissue environments could be recapitulated.

The most common way to control scaffold stiffness is by using polymers and cross-linkers at different concentrations or varying the molecular weight of the polymers. In this way, hydrogels formed by macromers of PEG and poly(lactic acid) (PLA), modifying the initial macromer concentration from $10 \%$ to $20 \%$ resulted in gels with elastic moduli increased from 60 to $500 \mathrm{kPa}$. The latter was used to restore initial function in chondrocytes and facilitate the production of cartilaginous production (Bryant et al, 2004). Besides, elastic modulus in HA and collagen hydrogels for example, was modulated by other groups simply changing the molecular weight of HA chains in the system, thus obtaining gels of enhanced mechanical properties without compromising the biological activity of HA (Owen and Shoichet, 2010, Xin et al, 2004).

Mooney's group usually uses a blend of high MW and low MW alginates that gives rise to highly cross-linked hydrogels but have a pre-gelled viscosity similar to that of pure high MW at low concentrations. Hence, they are able to decouple the rheological and mechanical properties, obtaining scaffolds with high elastic modulus while preventing cells from shear stress during encapsulation process (Kong et al, 2002). Recently, employing this procedure this group reported in an elegant study how MSCs were able to reorganize the adhesion ligands on the nanoscale in function of the stiffness offered by alginate matrix where they were encapsulated (Figure 7). This work suggested that the mentioned process may play an important role in MCS commitment (Huebsch et al, 2010).

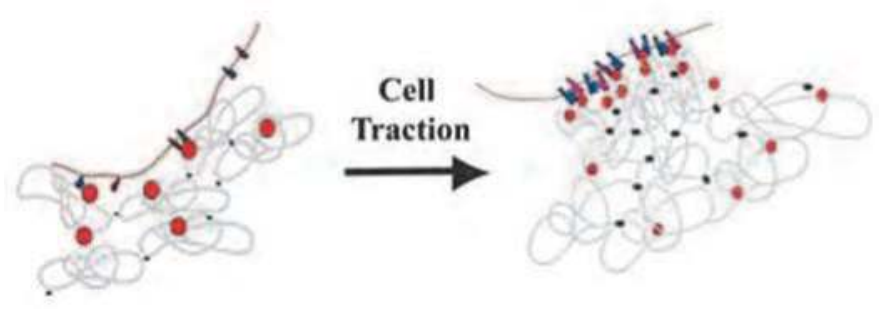

Fig. 7. Schematic depiction showing cell traction forces-mediated RGD nanoscale clustering. Reprinted and adapted by permission from Macmillan Publishers Ltd: Nature Materials (Huebsch et al, 2010), copyright 2010. http:// www.nature.com 
The precise mechanisms that operate behind all these effects are not fully understood yet. However, in the past years novel tools have been developed. Some include techniques to quantify the number of effective adhesions or assess the traction forces exerted on these anchorages (Kong et al, 2006, Huebsch and Mooney, 2007, Tan et al, 2003). For instance, Chen and co-workers described in a landmark study the use of collagen hydrogel anchored to microfabricated cantilevers that constrained the ECM surrogate at the same time they reported forces generated by encapsulated cells (NIH 3T3) (Owen and Shoichet, 2010, Legant et al, 2009). Moreover, authors proposed a computational model to predict the distributions of the stress gradients within the hydrogels, which may be useful to engineer complex tissues in vitro. Likely, this type of techniques together with future developments will generate fresh insight into the nature of these mechanisms, contributing to a more comprehensive design of cell-biomaterial interactions in the future.

\subsection{Presentation of chemical cues}

The regulation of soluble molecule distribution within 3D scaffolds becomes a difficult task, as the availability of the biomolecules is given on basis of the total concentration in the medium, diffusion rate within the gel, and cellular metabolic activity (Tibbitt and Anseth, 2009). In addition, artificial ECMs may also require the presence of growth factors and morphogens in a pharmacokinetic manner that resembles the natural cell niche. Thus, different approaches have been carried out in the attempt to regulate the kinetics and distribution of soluble factors. In an attempt to mimick the native ECM, where glycosaminoglycans act as depots for growth factors, heparin was incorporated to the scaffold backbone for posterior sequestering and controlled release of growth factors (Freeman et al, 2008, Yamaguchi and Kiick, 2005). Other approaches proposed covalently linking of specific ligands of the desired molecules to the scaffold (also known as phage display) (Willerth et al, 2007). Besides, by including multiple soluble factors within different encapsulation levels (e.g. PLG spheres within alginate hydrogels), it is possible to sustain a simultaneous or sequential factor delivery (Figure 8). The significance of exerting control over growth factors availability in time and space has been probed, for instance, in stem cell differentiation (Sands and Mooney, 2007, D'Amour et al, 2006) or therapeutic approaches to induce angiogenesis (Richardson et al, 2001, Sun et al, 2010).

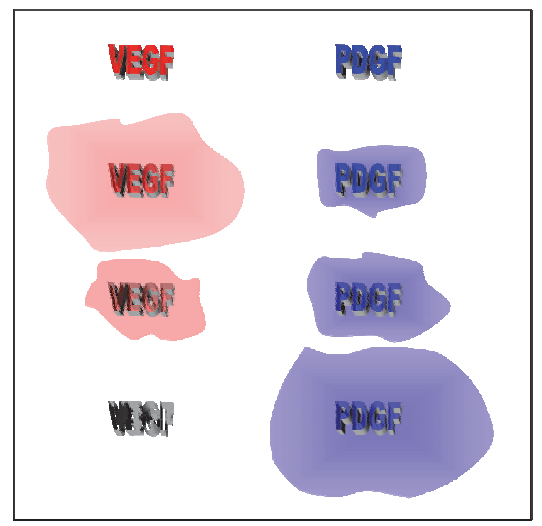

Fig. 8. Scheme illustrating a dual delivery of growth factors as a way to regulate the kinetics. 
As it occurs in 2D systems, soluble biomolecules often show improved bioactivity when they are presented directly attached to the hydrogel network (Shen et al, 2008). In addition to improved stability, the main advantage that offers covalenty immobilized growth factors is that it can be used to spatially direct cell behavior (e.g. chemotaxis or differentiation) (Shoichet, 2010). However, it is important to ensure that active domains of the molecules continue available upon covalent linkage.

On the other hand, gradients of morphogens, growth factors and cytokines are presented progressively in the physiological tissue, regulating basic biological phenomena such as, morphogenesis, chemotaxis and axogenesis (Choi et al, 2007). They play a key role not only in development phases, but also during processes like wound healing or tissue homeostasis. Such gradients can be introduced into 3D models, for instance, using the same micropatterning techniques described above to attach ligand moieties. In this way, endothelial cells (EC) tubule-like formation was guided through VEGF gradients patterned within RGD-modified agarose hydrogels (Aizawa et al, 2010).

Besides, microfluidics-based systems are also increasingly being used to generate gradients within 3D models (Lutolf et al, 2009b, Shoichet, 2010). These platforms represent one of the most accurate and robust ways to reproduce morphogen gradients given in vivo, as they allow small amounts of expensive factors to be patterned into scaffolds with tight control (Whitesides, 2006). Thus, some approaches have already been carried out. For example, embedding microfluidic channels directly within cell enclosing alginate scaffolds, and controlling the distributions and fluxes of solutes in the total volume by means of convective mass transfer (Choi et al, 2007) (Figure 9). Moreover, since biomolecules can also be tethered to the backbone of artificial ECMs, applying microfluidics technology with anchored proteins would give rise to more comprehensive and realistic ECM surrogates (Lutolf et al, 2009b).
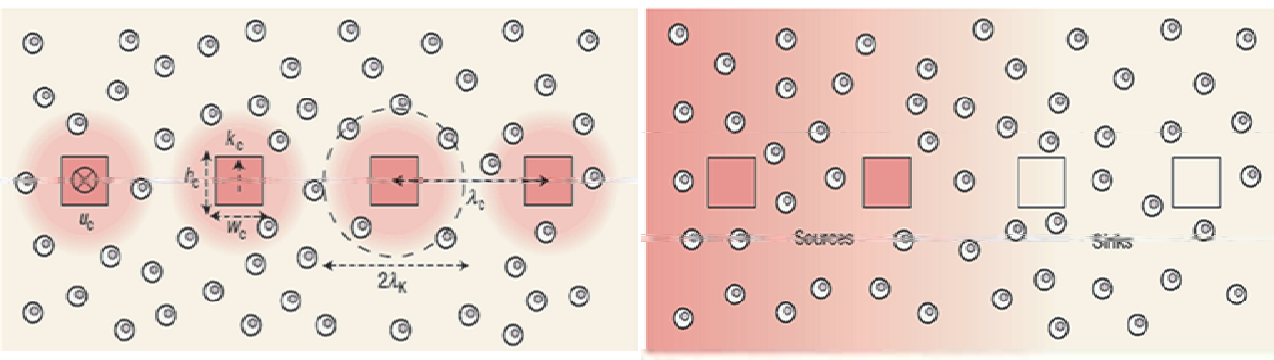

Fig. 9. Cross-sectional schematic depiction of cellular microfluidic scaffolds showing different manners to induce gradients of soluble factors. Reprinted and adapted by permission from Macmillan Publishers Ltd: Nature Materials (Choi et al, 2007), copyright 2007. http://www.nature.com

\subsection{Cell-cell interactions}

Defining the existing cell-cell interactions may result pivotal not only for diagnosis but also for therapeutics. Such importance is emphasized in case of culturing stem cells, for which the inclusion of support cells is often required. Cellular interplay has a notorious impact on stem cell behavior, although the variables that take part and their role are only starting to be understood (Lutolf et al, 2009b). 
In this respect, novel technologies like electropatterning are making possible to study cellcell interactions on the microscale. In this particular approach, dielectrophoretic forces were used to propel cells toward defined micropatterns within PEG photopolymerizable hydrogels and create cell clusters of precise size and shape. In this way, it was probed that microscale tissue arrangement affected in the biosynthesis of bovine articular chondrocytes (Albrecht et al, 2006).

It has been described that the size of embyoid bodies significantly influences ESC fate. In order to shed light on the mechanisms underlying such relation, PEG hydrogel microwells of different diameters were employed to create embryoid bodies of various sizes. Accordingly, larger embryoid bodies tended to prompt cardiogenesis, whereas smaller ones showed a more notable endothelial cell differentiation (Hwang et al, 2009).

\subsection{Dinamic matrices}

The native ECM is far from static. Therefore, the temporal and spatial variability typical of ECM's properties must also be introduced into our 3D models in order to simulate contextually meaningful and realistic microenvironments.

\subsubsection{Degradation (cell invasion and ECM deposition)}

One of the critical factors that can influence tissue morphogenesis is the ability of the matrix to be degraded. This process is fundamental to facilitate scaffold remodeling and ECM deposition by embebed cells. In addition, degradation allows cell migration and regulates the release of matrix-tethered biomolecules that induce different cellular functions (Moon et al, 2010). Apart from the scaffolds formed by ECM derived molecules, which present inherent degradability, it is possible to design inert matrices which can be degraded according to different strategies. For example, synthetic hydrogels can be designed to include degradable polymers within their network. Some studies describe the use of poly(lactic acid) (Metters et al, 2000) or poly(caprolactone) (Nuttelman et al, 2006) blocks in combination with PEG backbone. Similarly, the scaffolds can be built by co-polymerization of different ratios of degradable and non-degradable macromers (Bryant and Anseth, 2003). For all these types of designs, the degradation rate is governed by the number of hydrolytically labile bonds in the hydrogel, although in general, normal cellular processes are on another scale faster than the mentioned rate (Tibbitt and Anseth, 2009).

In alginate, a well known strategy to control the degradation rate of the scaffolds is the partially oxidation of the main chains to create controllable numbers of functional groups in the backbone susceptible to hydrolysis (Boontheekul et al, 2005). For instance, adjusting the degradation rate of different alginate scaffolds, it was observed that $\mathrm{C} 2 \mathrm{C} 12$ myoblasts exited the cell cycle to differentiate in more rapidly degrading gels, while those encapsulated within non-degradable gels showed higher proliferation levels (Boontheekul et al, 2007). Furthermore, by controlling the size of mismatch given by the network sites that mediate the ionic cross-linking, it is also possible to modulate the dissociation rate of chains in alginate scaffolds (Kong et al, 2004).

Hydrolytically labile hydrogels offer predictable degradation profiles, but such models do not allow for post-gelling alteration of the properties and degradation process is given uniformly and independently from cellular interactions. In order to enable cellularly driven matrix degradation, synthetic hydrogels, such as those formed by PEG acrylate, can be modified by Michael addition and photoinitiated reactions to include specific sequences that are recognized and cleaved by proteases like MMPs secreted by cells (Tibbitt and Anseth, 
2009, Lutolf et al, 2003). Following this strategy, it was demonstrated that fibroblasts entrapped within MMP-sensitive hydrogels were able to migrate, but effectively stopped upon MMP inhibition (Raeber et al, 2005). This approach allows cells to locally remodel their sourronding matrix and deposit their own ECM proteins, mimicking more realistically what occurs in vivo during wound healing, regeneration or tumor metastasis (Lutolf, 2009b).

\subsubsection{In situ alteration of biophysical and biochemical properties}

In order to make possible for the cells to rationally interpret the different biophysical and biochemical signals, the latter should be organized within spatio-temporal context, much like a phrase does in a conversation. If we exert local modifications of mentioned properties at certain times, we can force few cells to adopt decisions and develop new functionalities, which may give rise to start a hierarchical reorganization at the multicellular scale, reproducing those processes that take place in the nature (Lutolf, 2009a). Therefore, the creation of models that can be externally manipulated in time and space results very advantageous to study cell-ECM dynamic interplay.
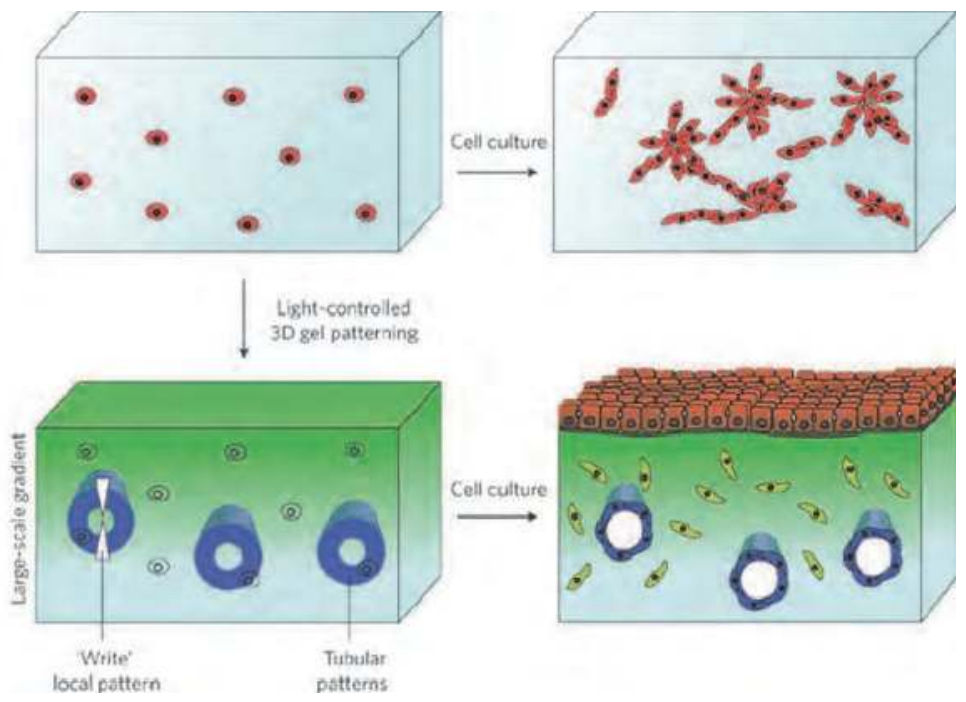

Fig. 10. Cells within homogeneous hydrogels give rise to disorganized cellular structures with no functionality, whereas light-mediated in situ patterned hydrogels may possibly prompt well defined structures and, ideally, tissue-like cell function. Reprinted by permission from Macmillan Publishers Ltd: Nature Materials (Lutolf, 2009a), copyright 2009. http://www.nature.com

With such aim, Anseth's group has developed a photodegradable PEG-based hydrogel model (Figure 10). The latter allows the creation of predictable degradation rate patterns and stiffness gradients in real-time under cytocompatible conditions (long-wavelength UV light). Moreover, thank to a single-photon visible light source, micrometer-scale resolution can be achieved for the manipulation of the gel properties (Kloxin et al, 2010c). Thus, using light guided gel patterning, it could be possible to condition cell behavior in situ within 3D environment, for example, by creating elastic modulus microgradients with well defined 
structures at desired times (Lutolf, 2009a) (Figure 10). This technology is not only limited to mediate matrix degradation, but it can be also employed to dynamically alter other biophysical and biochemical properties. For instance, by incorporating photolabile RGD moieties to the scaffolds, it was seen how chondrocytes showed an enhanced differentiation if adhesive moieties were removed at certain time points during 3D cell culturing (Kloxin et al, 2009).
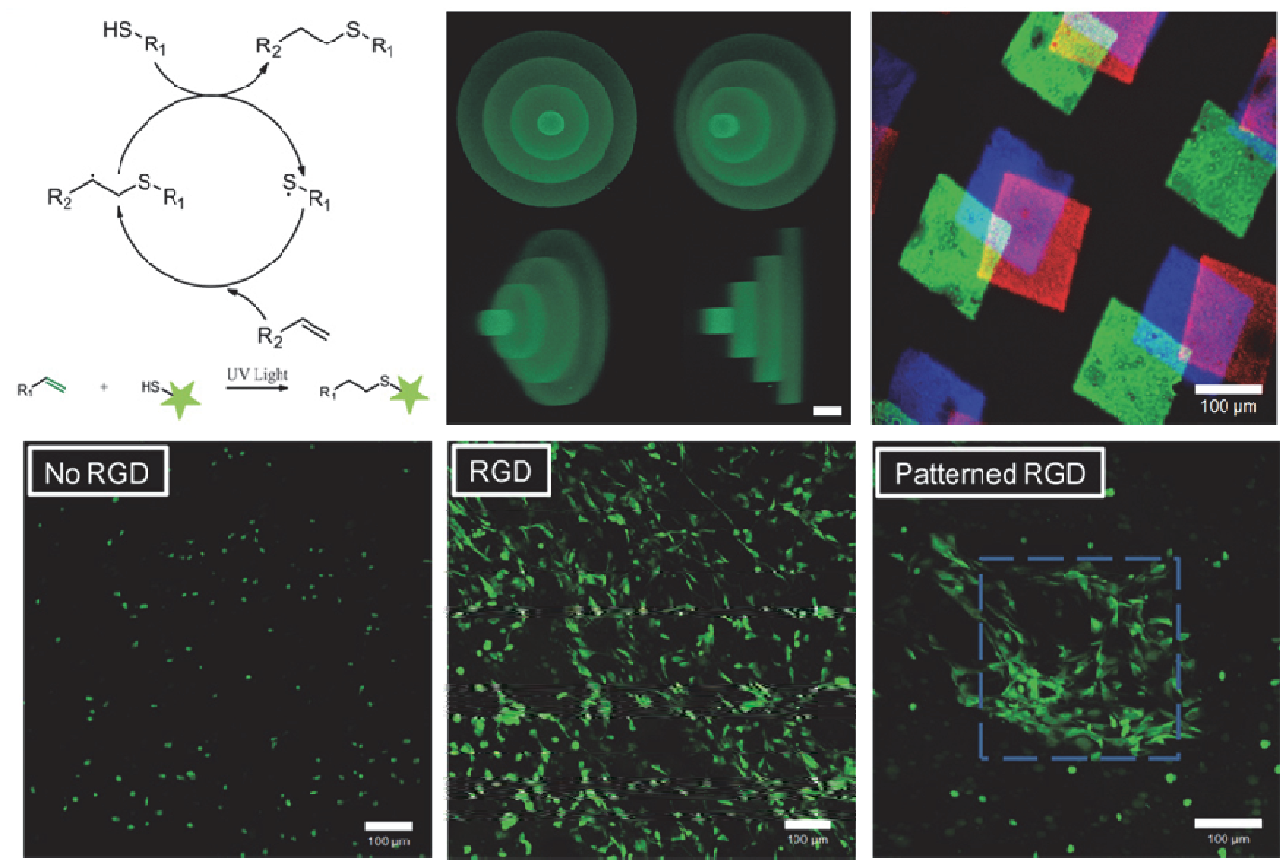

Fig. 11. Superior part of the figure shows from left to right the thiol-ene reaction employed to create in situ patterning of hydrogels and their fluorescence mycrographs (scale bars 50 and $100 \mu \mathrm{m}$ respectively). Bottom part displays cell spreading within in situ patterned hydrogels (scale bar $100 \mu \mathrm{m}$ ). Reprinted and adapted by permission from Macmillan Publishers Ltd: Nature Materials (DeForest et al, 2009), copyright 2009.

http://www.nature.com

Beyond these approaches, the same group is exploring an alternative strategy based on the "click" reactions, by which it is feasible to attach varying concentrations of biomolecules (adhesion ligands in this case) to the scaffold backbone by means of cytocompatible photolithographic patterning (micrometer resolution) after cell encapsulation (DeForest et al, 2009) (Figure 11). Taking into account that photoreactive groups for patterning are coupled with enzymatically degradable sequences, this approach represents a valuable strategy to build artificial ECMs in vitro with the possibility to modulate a wide number of variables in a spatio-temporal way. Nonetheless, as the technology advances and we gain new insights into the mechanisms that regulate cell-ECM interactions, we will be able to design more sophisticated and tailor-made models for the study of particular tissue physiologies. 


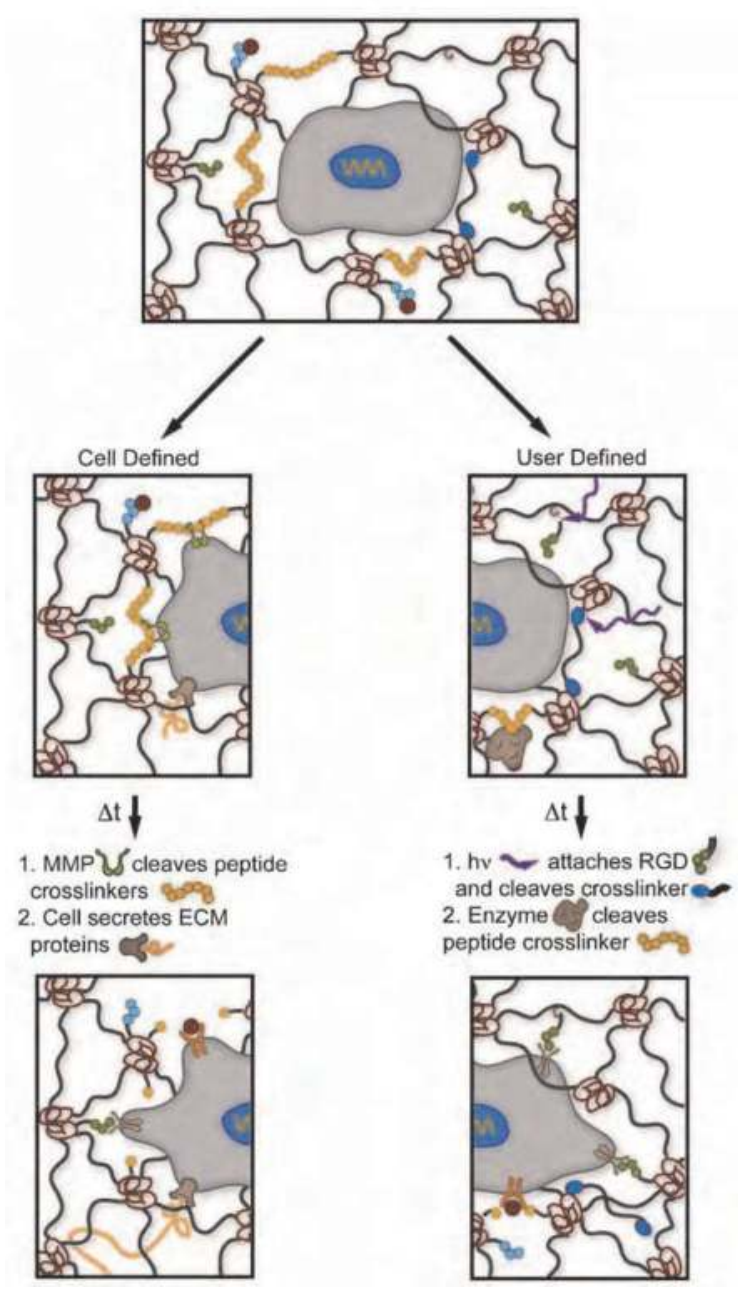

Fig. 12. Summary of 3D dynamic models that allow both cell and user defined matrix remodeling. Reproduced with permission from (Tibbitt and Anseth, 2009). Copyright WileyVCH Verlag GmbH \& Co. KGaA.

\subsection{Nanofabrication}

The necessity to understand in detail the nature of the native ECM has fueled new paths towards the fabrication of biomimetic models with nanoscale properties. Starting with the natural fibrous mesh of the ECM, it is possible to construct novel scaffolds with interconnected and porous structures formed by interwoven fibers with similar diameters to those presented by collagen fibers (Dvir et al, 2011). One of the main goals of such strategy is to allow the forces exerted by hosted cells for further material structural reorganization (Gelain et al, 2007). In this respect, electrospinning and molecular self-assembly are two of the most often employed techniques. 


\subsubsection{Electrospinning}

Elecrospinning is a technique in which different polymer fibers (natural and synthetic) can be deposited on a defined substrate by means of an electric field (Dvir et al, 2011). Resulting scaffolds present continuous fibers with high porosity and void space connectivity (Figure 13). The nanofibers can be orientated to recreate more or less arranged tissues (Kakade et al, 2007). Moreover, the structure can be designed to incorporate delivery systems, which control the release of cytokines, growth factors and drugs among others (Dvir et al, 2011, Ionescu et al, 2010, Dong et al, 2009). One important limitation, however, include the harshness of the fabrication process, which makes it impossible to encapsulate the cells in situ (Gelain et al, 2007), the weakness of resulted scaffolds, and the fact that diameters of the fibers only can emulate the thickest ranges found in the native ECM (50-500 nm) (Dvir et al, 2011).

\subsubsection{Molecular self-assembly}

This technique is based on the spontaneous arrangement of individual building-blocks into ordered and stable architecture by means of non-covalent bonds (Dvir et al, 2011, Hartgerink et al, 2001). In this sense, one of the most broadly described nanofiber is that formed by the amphiphile peptide (Zhang, 2003) (Figure 13). These nanofibilar matrices are very close in architecture to those composed of collagen in the native ECM, with $10 \mathrm{~nm}$ oscillating fibre diameter, pores ranging 5 to $200 \mathrm{~nm}$, and high water content (Zhang, 2003).
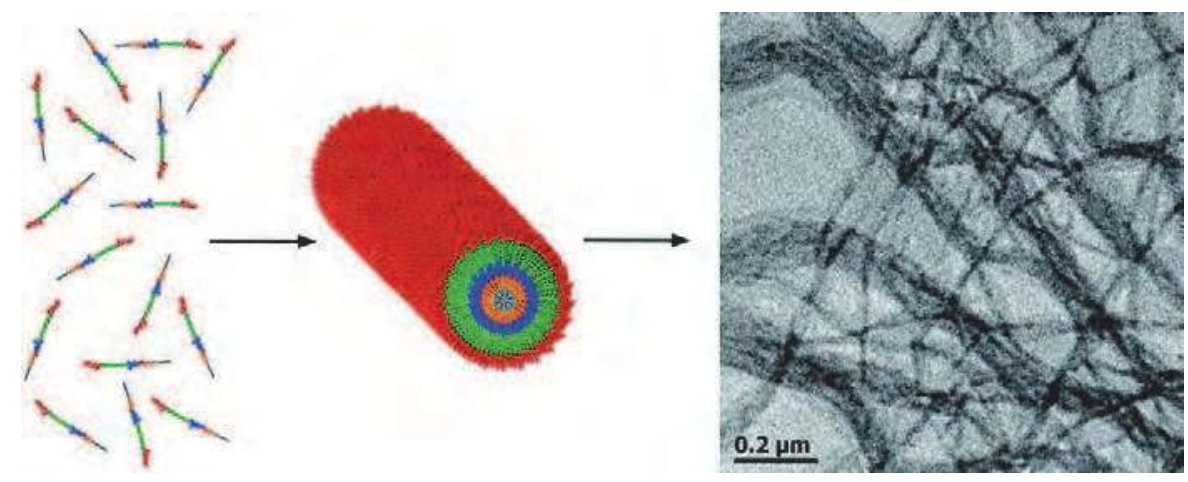

Fig. 13. Schematic representation of peptide amphiphile and Cryo-TEM images of resulting nanofibers. Reprinted with permission from (Rexeisen et al, 2010). Copyright 2009 American Chemical Society.

They can form hydrogels at near-physiological conditions, and in many cases the fiber morphology can also be controlled (Ryadnov and Woolfson, 2003). Furthermore, they can be designed to be sensitive to the action of proteases and include adhesion moieties in their backbone structure to support cell migration or induce linage differentiation. For instance, it was observed that such scaffolds presenting the laminin epitope IKVAV were able to prompt neural progenitor cells differentiation into neurons (Silva et al, 2004). Remarkably, some of these nanofibilar constructs such as PuraMatrix ${ }^{\mathrm{TM}}$, are now commercial products intended to be used in the fields of cell biology or tissue engineering (Lutolf, 2009b). On the contrary, due to the nature of the cross-linkages, the mechanical properties do not offer too much flexibility to be tuned (Kloxin et al, 2010b). 


\section{Design criteria}

As it can be observed, there is a wide range of possibilities to build our study model. Therefore, it is important to realize that design considerations should be varied according to the intended use and pursued goal. Thus, researchers interested in the study of cell migration through given biomolecule gradient in vitro, will possibly prefer the use of synthetic hydrogels like PEG to create their own patterns. On the contrary, those more interested in forming bone-like tissue within scaffolds in vivo will probably choose polymers that can be injected to form hydrogels once implanted. Similarly, it could be interesting to perform the preliminary and screening assays on 2D models, as they allow a straightforward and rapid processing of the studies, and then, move on to 3D models to analyze the effects thoroughly within more realistic environment. This is a typical workflow, always having in mind that the only true results are those validated in vivo.

Nonetheless, and in general terms, some of the most important features that an ideal 3D model should meet are the following ones:

- The building blocks (e.g. polymer of choice) should exhibit no cytotoxicity and offer a great biocompatibility to be implanted in the body without eliciting immune response (the latter only for in vivo applications).

- Fabrication process should be easy, reproducible and economically scalable. This concept includes material availability, production, purification and processing. Avoiding batch to batch variability is highly recommended.

- The ideal way to encapsulate cells is in situ, that is, while the hydrogel is forming. This means that cross-linking process should be performed under physiologic conditions without harmful products as a result of adverse side reactions.

- Fully transparent scaffolds allow for monitoring of enclosed cells, which is fundamental to study cell biology in vitro.

- The ideal model should offer wide possibilities to tune and modulate structural and mechanical properties such as elastic modulus, pore size or topography. For certain applications nanometric fiber-like scaffold could be appealing.

- Cell attachment should be provided to promote cell-substrate interactions. The possibility to alter ligand type, density or presentation patterns results in a more interesting model.

- It would be convenient not to leave the cellular uptake of soluble factors depending on the free diffusion. Some kind of attachment and/or delivery mechanism is advisable. Creation of gradients may result of great interest to study several cellular responses.

- The strategy of choice for matrix degradation should be considered. For instance, for certain applications it may be desirable to set a cell defined degradation (e.g. including MMP cleavable secuences), whereas for others it may be advantageous to degrade the matrix in a user defined way (e.g. incorporating hydrolytically labile units or sensitizing the polymer to hydrolysis). Degradation products should be non-toxic.

- All biophysical and biochemical properties should allow independent manipulability from each other. For example, increasing polymer concentration to achieve a higher elastic modulus should neither affect adhesion-ligand density nor mode of presentation.

- Spatio-temporal dynamics should be taken into account regarding growth factors/morphogen presentation and kinetics, matrix composition, or adhesion ligand availability for example. 
- In case the scaffold is intended to be used in vivo, it is highly recommendable to employ injectable hydrogels, avoiding surgery procedures.

Finally, there is no single model able to recapitulate the whole complexity of every tissue type ECM. Many authors agree on the fact that high level of complexity is not necessary for many applications, and indeed simpler and practical models are enough to solve some specific questions (Sands and Mooney, 2007, Fisher et al, 2010, Griffith and Swartz, 2006). In fact, cells enclosed within 3D matrices rapidly remodel their microenvironment depositing their own ECM molecules (Lutolf, 2009b, Zhou et al, 2008). For that reason, it is possible to compensate the lack of such complexity with artificial systems capable of inducing desired effects to the hosted cells in a more efficient and rational way. In this regard, it was demonstrated how merely presenting tethered small-molecule chemical functional groups was enough to recreate unique chemical environments and induce multiple MSC differentiated lineages (Benoit et al, 2008). Nonetheless, if the goal is obtaining tissue-like structures for regenerative medicine for example, higher complexity levels in time and space are absolutely justified (Lutolf, 2009b).

\section{Conclusion}

Artificial ECMs are guiding our nascent understanding of cellular microenvironment and how the basic building blocks of biological systems are integrated in the dynamic landscape that represents tissue physiology. Elucidating the mechanisms by which cells receive information from their microenvironment will serve us to design new biomimetic models that precisely regulate cellular gene expression. Likewise, biomaterial strategies are bridging the gap in many scientific fields, as they have become an imprescindible tool in tissue engineering or regenerative medicine among others. Advances in biological science and technology will give rise in the future to new and more sophisticated biomaterial designs.

\section{Acknowledgment}

E. Santos thanks the Basque Government (Department of Education, Universities and Research) for the fellowship grant.

\section{References}

Aizawa, Y.; Wylie, R. \& Shoichet, M. Endothelial cell guidance in 3D patterned scaffolds. (2010). Advanced materials (Deerfield Beach, Fla.), Vol.22, No.43, pp. 4831-4835, ISSN 1521-4095; 0935-9648

Alberti, K.; Davey, R.E.; Onishi, K.; George, S.; Salchert, K.; Seib, F.P.; Bornhauser, M.; Pompe, T.; Nagy, A.; Werner, C. \& Zandstra, P.W. Functional immobilization of signaling proteins enables control of stem cell fate. (2008). Nature methods, Vol.5, No.7, pp. 645-650, ISSN 1548-7105; 1548-7091

Albrecht, D.R.; Underhill, G.H.; Wassermann, T.B.; Sah, R.L. \& Bhatia, S.N. Probing the role of multicellular organization in three-dimensional microenvironments. (2006). Nature methods, Vol.3, No.5, pp. 369-375, ISSN 1548-7091; 1548-7091

Anderson, D.G.; Levenberg, S. \& Langer, R. Nanoliter-scale synthesis of arrayed biomaterials and application to human embryonic stem cells. (2004). Nature biotechnology, Vol.22, No.7, pp. 863-866, ISSN 1087-0156; 1087-0156 
Ashe, H.L. \& Briscoe, J. The interpretation of morphogen gradients. (2006). Development (Cambridge, England), Vol.133, No.3, pp. 385-394, ISSN 0950-1991; 0950-1991

Ayres, C.E.; Jha, B.S.; Sell, S.A.; Bowlin, G.L. \& Simpson, D.G. Nanotechnology in the design of soft tissue scaffolds: innovations in structure and function. (2010). Wiley interdisciplinary reviews.Nanomedicine and nanobiotechnology, Vol.2, No.1, pp. 20-34, ISSN 1939-0041; 1939-0041

Bauer, A.L.; Jackson, T.L. \& Jiang, Y. Topography of extracellular matrix mediates vascular morphogenesis and migration speeds in angiogenesis. (2009). PLoS computational biology, Vol.5, No.7, pp. e1000445, ISSN 1553-7358; 1553-734X

Benoit, D.S.; Schwartz, M.P.; Durney, A.R. \& Anseth, K.S. Small functional groups for controlled differentiation of hydrogel-encapsulated human mesenchymal stem cells. (2008). Nature materials, Vol.7, No.10, pp. 816-823, ISSN 1476-1122; 1476-1122

Berry, M.F.; Engler, A.J.; Woo, Y.J.; Pirolli, T.J.; Bish, L.T.; Jayasankar, V.; Morine, K.J.; Gardner, T.J.; Discher, D.E. \& Sweeney, H.L. Mesenchymal stem cell injection after myocardial infarction improves myocardial compliance. (2006). American journal of physiology.Heart and circulatory physiology, Vol.290, No.6, pp. H2196-203, ISSN 03636135; 0363-6135

Bettinger, C.J.; Langer, R. \& Borenstein, J.T. Engineering substrate topography at the microand nanoscale to control cell function. (2009). Angewandte Chemie (International ed.in English), Vol.48, No.30, pp. 5406-5415, ISSN 1521-3773; 1433-7851

Boontheekul, T.; Kong, H.J. \& Mooney, D.J. Controlling alginate gel degradation utilizing partial oxidation and bimodal molecular weight distribution. (2005). Biomaterials, Vol.26, No.15, pp. 2455-2465, ISSN 0142-9612; 0142-9612

Boontheekul, T.; Hill, E.E.; Kong, H.J. \& Mooney, D.J. Regulating myoblast phenotype through controlled gel stiffness and degradation. (2007). Tissue engineering, Vol.13, No.7, pp. 1431-1442, ISSN 1076-3279; 1076-3279

Brafman, D.A.; de Minicis, S.; Seki, E.; Shah, K.D.; Teng, D.; Brenner, D.; Willert, K. \& Chien, $\mathrm{S}$. Investigating the role of the extracellular environment in modulating hepatic stellate cell biology with arrayed combinatorial microenvironments. (2009). Integrative biology : quantitative biosciences from nano to macro, Vol.1, No.8-9, pp. 513524, ISSN 1757-9708; 1757-9694

Bryant, S.J. \& Anseth, K.S. Controlling the spatial distribution of ECM components in degradable PEG hydrogels for tissue engineering cartilage. (2003). Journal of biomedical materials research.Part A, Vol.64, No.1, pp. 70-79, ISSN 1549-3296; 15493296

Bryant, S.J.; Bender, R.J.; Durand, K.L. \& Anseth, K.S. Encapsulating chondrocytes in degrading PEG hydrogels with high modulus: engineering gel structural changes to facilitate cartilaginous tissue production. (2004). Biotechnology and bioengineering, Vol.86, No.7, pp. 747-755, ISSN 0006-3592; 0006-3592

Chen, C.S.; Mrksich, M.; Huang, S.; Whitesides, G.M. \& Ingber, D.E. Geometric control of cell life and death. (1997). Science (New York, N.Y.), Vol.276, No.5317, pp. 1425-1428, ISSN 0036-8075; 0036-8075

Choi, N.W.; Cabodi, M.; Held, B.; Gleghorn, J.P.; Bonassar, L.J. \& Stroock, A.D. Microfluidic scaffolds for tissue engineering. (2007). Nature materials, Vol.6, No.11, pp. 908-915, ISSN 1476-1122; 1476-1122 
Chung, B.G.; Flanagan, L.A.; Rhee, S.W.; Schwartz, P.H.; Lee, A.P.; Monuki, E.S. \& Jeon, N.L. Human neural stem cell growth and differentiation in a gradient-generating microfluidic device. (2005). Lab on a chip, Vol.5, No.4, pp. 401-406, ISSN 1473-0197; 1473-0189

Cohen, E.D.; Ihida-Stansbury, K.; Lu, M.M.; Panettieri, R.A.; Jones, P.L. \& Morrisey, E.E. Wnt signaling regulates smooth muscle precursor development in the mouse lung via a tenascin C/PDGFR pathway. (2009). The Journal of clinical investigation, Vol.119, No.9, pp. 2538-2549, ISSN 1558-8238; 0021-9738

Comisar, W.A.; Kazmers, N.H.; Mooney, D.J. \& Linderman, J.J. Engineering RGD nanopatterned hydrogels to control preosteoblast behavior: a combined computational and experimental approach. (2007). Biomaterials, Vol.28, No.30, pp. 4409-4417, ISSN 0142-9612; 0142-9612

Cukierman, E.; Pankov, R.; Stevens, D.R. \& Yamada, K.M. Taking cell-matrix adhesions to the third dimension. (2001). Science (New York, N.Y.), Vol.294, No.5547, pp. 17081712, ISSN 0036-8075; 0036-8075

Daley, W.P.; Peters, S.B. \& Larsen, M. Extracellular matrix dynamics in development and regenerative medicine. (2008). Journal of cell science, Vol.121, No.Pt 3, pp. 255-264, ISSN 0021-9533; 0021-9533

D'Amour, K.A.; Bang, A.G.; Eliazer, S.; Kelly, O.G.; Agulnick, A.D.; Smart, N.G.; Moorman, M.A.; Kroon, E.; Carpenter, M.K. \& Baetge, E.E. Production of pancreatic hormoneexpressing endocrine cells from human embryonic stem cells. (2006). Nature biotechnology, Vol.24, No.11, pp. 1392-1401, ISSN 1087-0156; 1087-0156

DeForest, C.A.; Polizzotti, B.D. \& Anseth, K.S. Sequential click reactions for synthesizing and patterning three-dimensional cell microenvironments. (2009). Nature materials, Vol.8, No.8, pp. 659-664, ISSN 1476-1122; 1476-1122

Discher, D.E.; Janmey, P. \& Wang, Y.L. Tissue cells feel and respond to the stiffness of their substrate. (2005). Science (New York, N.Y.), Vol.310, No.5751, pp. 1139-1143, ISSN 1095-9203; 0036-8075

Discher, D.E.; Mooney, D.J. \& Zandstra, P.W. Growth factors, matrices, and forces combine and control stem cells. (2009). Science (New York, N.Y.), Vol.324, No.5935, pp. 16731677, ISSN 1095-9203; 0036-8075

Dong, B.; Smith, M.E. \& Wnek, G.E. Encapsulation of multiple biological compounds within a single electrospun fiber. (2009). Small (Weinheim an der Bergstrasse, Germany), Vol.5, No.13, pp. 1508-1512, ISSN 1613-6829; 1613-6810

Dvir, T.; Timko, B.P.; Kohane, D.S. \& Langer, R. Nanotechnological strategies for engineering complex tissues. (2011). Nature nanotechnology, Vol.6, No.1, pp. 13-22, ISSN 1748-3395; 1748-3387

Engler, A.J.; Sen, S.; Sweeney, H.L. \& Discher, D.E. Matrix elasticity directs stem cell lineage specification. (2006). Cell, Vol.126, No.4, pp. 677-689, ISSN 0092-8674; 0092-8674

Fan, V.H.; Tamama, K.; Au, A.; Littrell, R.; Richardson, L.B.; Wright, J.W.; Wells, A. \& Griffith, L.G. Tethered epidermal growth factor provides a survival advantage to mesenchymal stem cells. (2007). Stem cells (Dayton, Ohio), Vol.25, No.5, pp. 12411251, ISSN 1066-5099; 1066-5099

Fisher, O.Z.; Khademhosseini, A.; Langer, R. \& Peppas, N.A. Bioinspired materials for controlling stem cell fate. (2010). Accounts of Chemical Research, Vol.43, No.3, pp. 419-428, ISSN 1520-4898; 0001-4842 
Flaim, C.J.; Chien, S. \& Bhatia, S.N. An extracellular matrix microarray for probing cellular differentiation. (2005). Nature methods, Vol.2, No.2, pp. 119-125, ISSN 1548-7091; 1548-7091

Freed, L.E.; Guilak, F.; Guo, X.E.; Gray, M.L.; Tranquillo, R.; Holmes, J.W.; Radisic, M.; Sefton, M.V.; Kaplan, D. \& Vunjak-Novakovic, G. Advanced tools for tissue engineering: scaffolds, bioreactors, and signaling. (2006). Tissue engineering, Vol.12, No.12, pp. 3285-3305, ISSN 1076-3279; 1076-3279

Freeman, I.; Kedem, A. \& Cohen, S. The effect of sulfation of alginate hydrogels on the specific binding and controlled release of heparin-binding proteins. (2008). Biomaterials, Vol.29, No.22, pp. 3260-3268, ISSN 0142-9612; 0142-9612

Frey, M.T. \& Wang, Y.L. A photo-modulatable material for probing cellular responses to substrate rigidity. (2009). Soft matter, Vol.5, pp. 1918-1924, ISSN 1744-6848; 1744$683 X$

Gardel, M. \& Schwarz, U. Cell-substrate interactions. (2010). Journal of physics.Condensed matter : an Institute of Physics journal, Vol.22, No.19, pp. 190301, ISSN 0953-8984; 0953-8984

Gelain, F.; Horii, A. \& Zhang, S. Designer self-assembling peptide scaffolds for 3-d tissue cell cultures and regenerative medicine. (2007). Macromolecular bioscience, Vol.7, No.5, pp. 544-551, ISSN 1616-5187; 1616-5187

Gilbert, P.M.; Havenstrite, K.L.; Magnusson, K.E.; Sacco, A.; Leonardi, N.A.; Kraft, P.; Nguyen, N.K.; Thrun, S.; Lutolf, M.P. \& Blau, H.M. Substrate elasticity regulates skeletal muscle stem cell self-renewal in culture. (2010). Science (New York, N.Y.), Vol.329, No.5995, pp. 1078-1081, ISSN 1095-9203; 0036-8075

Griffith, L.G. \& Swartz, M.A. Capturing complex 3D tissue physiology in vitro. (2006). Nature reviews.Molecular cell biology, Vol.7, No.3, pp. 211-224, ISSN 1471-0072; 14710072

Guilak, F.; Cohen, D.M.; Estes, B.T.; Gimble, J.M.; Liedtke, W. \& Chen, C.S. Control of stem cell fate by physical interactions with the extracellular matrix. (2009). Cell stem cell, Vol.5, No.1, pp. 17-26, ISSN 1875-9777

Hartgerink, J.D.; Beniash, E. \& Stupp, S.I. Self-assembly and mineralization of peptideamphiphile nanofibers. (2001). Science (New York, N.Y.), Vol.294, No.5547, pp. 16841688, ISSN 0036-8075; 0036-8075

Heino, J. \& Kapyla, J. Cellular receptors of extracellular matrix molecules. (2009). Current pharmaceutical design, Vol.15, No.12, pp. 1309-1317, ISSN 1873-4286; 1381-6128

Hsiong, S.X.; Huebsch, N.; Fischbach, C.; Kong, H.J. \& Mooney, D.J. Integrin-adhesion ligand bond formation of preosteoblasts and stem cells in three-dimensional RGD presenting matrices. (2008). Biomacromolecules, Vol.9, No.7, pp. 1843-1851, ISSN 1526-4602; 1525-7797

Huang, N.F.; Patel, S.; Thakar, R.G.; Wu, J.; Hsiao, B.S.; Chu, B.; Lee, R.J. \& Li, S. Myotube assembly on nanofibrous and micropatterned polymers. (2006). Nano letters, Vol.6, No.3, pp. 537-542, ISSN 1530-6984; 1530-6984

Huebsch, N. \& Mooney, D.J. Inspiration and application in the evolution of biomaterials. (2009). Nature, Vol.462, No.7272, pp. 426-432, ISSN 1476-4687; 0028-0836

Huebsch, N.; Arany, P.R.; Mao, A.S.; Shvartsman, D.; Ali, O.A.; Bencherif, S.A.; RiveraFeliciano, J. \& Mooney, D.J. Harnessing traction-mediated manipulation of the 
cell/matrix interface to control stem-cell fate. (2010). Nature materials, Vol.9, No.6, pp. 518-526, ISSN 1476-1122; 1476-1122

Huebsch, N.D. \& Mooney, D.J. Fluorescent resonance energy transfer: A tool for probing molecular cell-biomaterial interactions in three dimensions. (2007). Biomaterials, Vol.28, No.15, pp. 2424-2437, ISSN 0142-9612; 0142-9612

Hwang, Y.S.; Chung, B.G.; Ortmann, D.; Hattori, N.; Moeller, H.C. \& Khademhosseini, A. Microwell-mediated control of embryoid body size regulates embryonic stem cell fate via differential expression of WNT5a and WNT11. (2009). Proceedings of the National Academy of Sciences of the United States of America, Vol.106, No.40, pp. 1697816983, ISSN 1091-6490; 0027-8424

Hynes, R.O. The extracellular matrix: not just pretty fibrils. (2009). Science (New York, N.Y.), Vol.326, No.5957, pp. 1216-1219, ISSN 1095-9203; 0036-8075

Ionescu, L.C.; Lee, G.C.; Sennett, B.J.; Burdick, J.A. \& Mauck, R.L. An anisotropic nanofiber/microsphere composite with controlled release of biomolecules for fibrous tissue engineering. (2010). Biomaterials, Vol.31, No.14, pp. 4113-4120, ISSN 1878-5905; 0142-9612

Irvine, D.J.; Hue, K.A.; Mayes, A.M. \& Griffith, L.G. Simulations of cell-surface integrin binding to nanoscale-clustered adhesion ligands. (2002). Biophysical journal, Vol.82, No.1 Pt 1, pp. 120-132, ISSN 0006-3495; 0006-3495

Isenberg, B.C.; Dimilla, P.A.; Walker, M.; Kim, S. \& Wong, J.Y. Vascular smooth muscle cell durotaxis depends on substrate stiffness gradient strength. (2009). Biophysical journal, Vol.97, No.5, pp. 1313-1322, ISSN 1542-0086; 0006-3495

Kakade, M.V.; Givens, S.; Gardner, K.; Lee, K.H.; Chase, D.B. \& Rabolt, J.F. Electric field induced orientation of polymer chains in macroscopically aligned electrospun polymer nanofibers. (2007). Journal of the American Chemical Society, Vol.129, No.10, pp. 2777-2782, ISSN 0002-7863; 0002-7863

Keskar, V.; Marion, N.W.; Mao, J.J. \& Gemeinhart, R.A. In vitro evaluation of macroporous hydrogels to facilitate stem cell infiltration, growth, and mineralization. (2009). Tissue engineering.Part A, Vol.15, No.7, pp. 1695-1707, ISSN 1937-335X; 1937-3341

Khire, V.S.; Benoit, D.S.W.; Anseth, K.S. \& Bowman, C.N. Ultrathin gradient films using thiol-ene polymerizations. (2006). Journal of Polymer Science Part A: Polymer Chemistry, Vol.44, No.24, pp. 7027-7039, ISSN 1099-0518

Kloxin, A.M.; Kasko, A.M.; Salinas, C.N. \& Anseth, K.S. Photodegradable hydrogels for dynamic tuning of physical and chemical properties. (2009). Science (New York, N.Y.), Vol.324, No.5923, pp. 59-63, ISSN 1095-9203; 0036-8075

Kloxin, A.M.; Benton, J.A. \& Anseth, K.S. In situ elasticity modulation with dynamic substrates to direct cell phenotype. (2010a). Biomaterials, Vol.31, No.1, pp. 1-8, ISSN 1878-5905; 0142-9612

Kloxin, A.M.; Kloxin, C.J.; Bowman, C.N. \& Anseth, K.S. Mechanical properties of cellularly responsive hydrogels and their experimental determination. (2010b). Advanced materials (Deerfield Beach, Fla.), Vol.22, No.31, pp. 3484-3494, ISSN 1521-4095; 09359648

Kloxin, A.M.; Tibbitt, M.W.; Kasko, A.M.; Fairbairn, J.A. \& Anseth, K.S. Tunable hydrogels for external manipulation of cellular microenvironments through controlled photodegradation. (2010c). Advanced materials (Deerfield Beach, Fla.), Vol.22, No.1, pp. 61-66, ISSN 1521-4095; 0935-9648 
Kong, H.?.; Alsberg, E.; Kaigler, D.; Lee, K.? \& Mooney, D.?. Controlling Degradation of Hydrogels via the Size of Crosslinked Junctions. (2004). Advanced Materials, Vol.16, No.21, pp. 1917-1921, ISSN 1521-4095

Kong, H.J.; Boontheekul, T. \& Mooney, D.J. Quantifying the relation between adhesion ligand-receptor bond formation and cell phenotype. (2006). Proceedings of the National Academy of Sciences of the United States of America, Vol.103, No.49, pp. 1853418539, ISSN 0027-8424; 0027-8424

Kong, H.J. \& Mooney, D.J. Microenvironmental regulation of biomacromolecular therapies. (2007). Nature reviews.Drug discovery, Vol.6, No.6, pp. 455-463, ISSN 1474-1776; 14741776

Kong, H.; Lee, K.Y. \& Mooney, D.J. Decoupling the dependence of rheological/mechanical properties of hydrogels from solids concentration. (2002). Polymer, Vol.43, No.23, pp. 6239-6246, ISSN 0032-3861

LaBarge, M.A.; Nelson, C.M.; Villadsen, R.; Fridriksdottir, A.; Ruth, J.R.; Stampfer, M.R.; Petersen, O.W. \& Bissell, M.J. Human mammary progenitor cell fate decisions are products of interactions with combinatorial microenvironments. (2009). Integrative biology : quantitative biosciences from nano to macro, Vol.1, No.1, pp. 70-79, ISSN 17579708; 1757-9694

Langer, R. \& Vacanti, J.P. Tissue engineering. (1993). Science (New York, N.Y.), Vol.260, No.5110, pp. 920-926, ISSN 0036-8075; 0036-8075

Lee, K.Y.; Alsberg, E.; Hsiong, S.; Comisar, W.; Linderman, J.; Ziff, R. \& Mooney, D. Nanoscale Adhesion Ligand Organization Regulates Osteoblast Proliferation and Differentiation. (2004). Nano Letters, Vol.4, No.8, pp. 1501-1506, ISSN 1530-6984

Lee, S.H.; Moon, J.J. \& West, J.L. Three-dimensional micropatterning of bioactive hydrogels via two-photon laser scanning photolithography for guided 3D cell migration. (2008). Biomaterials, Vol.29, No.20, pp. 2962-2968, ISSN 0142-9612; 0142-9612

Lee, W.; Cho, N.J.; Xiong, A.; Glenn, J.S. \& Frank, C.W. Hydrophobic nanoparticles improve permeability of cell-encapsulating poly(ethylene glycol) hydrogels while maintaining patternability. (2010). Proceedings of the National Academy of Sciences of the United States of America, Vol.107, No.48, pp. 20709-20714, ISSN 1091-6490; 00278424

Legant, W.R.; Pathak, A.; Yang, M.T.; Deshpande, V.S.; McMeeking, R.M. \& Chen, C.S. Microfabricated tissue gauges to measure and manipulate forces from 3D microtissues. (2009). Proceedings of the National Academy of Sciences of the United States of America, Vol.106, No.25, pp. 10097-10102, ISSN 1091-6490; 0027-8424

Levental, K.R.; Yu, H.; Kass, L.; Lakins, J.N.; Egeblad, M.; Erler, J.T.; Fong, S.F.; Csiszar, K.; Giaccia, A.; Weninger, W.; Yamauchi, M.; Gasser, D.L. \& Weaver, V.M. Matrix crosslinking forces tumor progression by enhancing integrin signaling. (2009). Cell, Vol.139, No.5, pp. 891-906, ISSN 1097-4172; 0092-8674

Lo, C.M.; Wang, H.B.; Dembo, M. \& Wang, Y.L. Cell movement is guided by the rigidity of the substrate. (2000). Biophysical journal, Vol.79, No.1, pp. 144-152, ISSN 0006-3495; 0006-3495

Luo, Y. \& Shoichet, M.S. A photolabile hydrogel for guided three-dimensional cell growth and migration. (2004). Nature materials, Vol.3, No.4, pp. 249-253, ISSN 1476-1122; 1476-1122 
Lutolf, M.P.; Lauer-Fields, J.L.; Schmoekel, H.G.; Metters, A.T.; Weber, F.E.; Fields, G.B. \& Hubbell, J.A. Synthetic matrix metalloproteinase-sensitive hydrogels for the conduction of tissue regeneration: engineering cell-invasion characteristics. (2003). Proceedings of the National Academy of Sciences of the United States of America, Vol.100, No.9, pp. 5413-5418, ISSN 0027-8424; 0027-8424

Lutolf, M.P. \& Hubbell, J.A. Synthetic biomaterials as instructive extracellular microenvironments for morphogenesis in tissue engineering. (2005). Nature biotechnology, Vol.23, No.1, pp. 47-55, ISSN 1087-0156; 1087-0156

Lutolf, M.P. Biomaterials: Spotlight on hydrogels. (2009a). Nature materials, Vol.8, No.6, pp. 451-453, ISSN 1476-1122; 1476-1122

Lutolf, M.P. Integration column: artificial ECM: expanding the cell biology toolbox in 3D. (2009b). Integrative biology : quantitative biosciences from nano to macro, Vol.1, No.3, pp. 235-241, ISSN 1757-9708; 1757-9694

Lutolf, M.P.; Doyonnas, R.; Havenstrite, K.; Koleckar, K. \& Blau, H.M. Perturbation of single hematopoietic stem cell fates in artificial niches. (2009a). Integrative biology: quantitative biosciences from nano to macro, Vol.1, No.1, pp. 59-69, ISSN 1757-9708; 1757-9694

Lutolf, M.P.; Gilbert, P.M. \& Blau, H.M. Designing materials to direct stem-cell fate. (2009b). Nature, Vol.462, No.7272, pp. 433-441, ISSN 1476-4687; 0028-0836

Maheshwari, G.; Brown, G.; Lauffenburger, D.A.; Wells, A. \& Griffith, L.G. Cell adhesion and motility depend on nanoscale RGD clustering. (2000). Journal of cell science, Vol.113 ( Pt 10), No.Pt 10, pp. 1677-1686, ISSN 0021-9533; 0021-9533

McBeath, R.; Pirone, D.M.; Nelson, C.M.; Bhadriraju, K. \& Chen, C.S. Cell shape, cytoskeletal tension, and RhoA regulate stem cell lineage commitment. (2004). Developmental cell, Vol.6, No.4, pp. 483-495, ISSN 1534-5807; 1534-5807

Mei, Y.; Hollister-Lock, J.; Bogatyrev, S.R.; Cho, S.W.; Weir, G.C.; Langer, R. \& Anderson, D.G. A high throughput micro-array system of polymer surfaces for the manipulation of primary pancreatic islet cells. (2010). Biomaterials, Vol.31, No.34, pp. 8989-8995, ISSN 1878-5905; 0142-9612

Mei, Y.; Gerecht, S.; Taylor, M.; Urquhart, A.J.; Bogatyrev, S.R.; Cho, S.; Davies, M.C.; Alexander, M.R.; Langer, R.S. \& Anderson, D.G. Mapping the Interactions among Biomaterials, Adsorbed Proteins, and Human Embryonic Stem Cells. (2009). Advanced Materials, Vol.21, No.27, pp. 2781-2786, ISSN 1521-4095

Metters, A.T.; Anseth, K.S. \& Bowman, C.N. Fundamental studies of a novel, biodegradable PEG-b-PLA hydrogel. (2000). Polymer, Vol.41, No.11, pp. 3993-4004, ISSN 0032-3861

Moon, J.J.; Saik, J.E.; Poche, R.A.; Leslie-Barbick, J.E.; Lee, S.H.; Smith, A.A.; Dickinson, M.E. \& West, J.L. Biomimetic hydrogels with pro-angiogenic properties. (2010). Biomaterials, Vol.31, No.14, pp. 3840-3847, ISSN 1878-5905; 0142-9612

Mooney, D.J. \& Vandenburgh, H. Cell delivery mechanisms for tissue repair. (2008). Cell stem cell, Vol.2, No.3, pp. 205-213, ISSN 1875-9777

Musoke-Zawedde, P. \& Shoichet, M.S. Anisotropic three-dimensional peptide channels guide neurite outgrowth within a biodegradable hydrogel matrix. (2006). Biomedical materials (Bristol, England), Vol.1, No.3, pp. 162-169, ISSN 1748-605X; 1748-6041

Nuttelman, C.R.; Kloxin, A.M. \& Anseth, K.S. Temporal changes in peg hydrogel structure influence human mesenchymal stem cell proliferation and matrix mineralization. 
(2006). Advances in Experimental Medicine and Biology, Vol.585, pp. 135-149, ISSN 0065-2598; 0065-2598

Orive, G.; De Castro, M.; Kong, H.J.; Hernandez, R.M.; Ponce, S.; Mooney, D.J. \& Pedraz, J.L. Bioactive cell-hydrogel microcapsules for cell-based drug delivery. (2009). Journal of controlled release : official journal of the Controlled Release Society, Vol.135, No.3, pp. 203-210, ISSN 1873-4995; 0168-3659

Owen, S.C. \& Shoichet, M.S. Design of three-dimensional biomimetic scaffolds. (2010). Journal of biomedical materials research.Part A, Vol.94, No.4, pp. 1321-1331, ISSN 15524965; 1549-3296

Peters, A.; Brey, D.M. \& Burdick, J.A. High-throughput and combinatorial technologies for tissue engineering applications. (2009). Tissue engineering.Part B, Reviews, Vol.15, No.3, pp. 225-239, ISSN 1937-3376; 1937-3368

Petersen, O.W.; Ronnov-Jessen, L.; Howlett, A.R. \& Bissell, M.J. Interaction with basement membrane serves to rapidly distinguish growth and differentiation pattern of normal and malignant human breast epithelial cells. (1992). Proceedings of the National Academy of Sciences of the United States of America, Vol.89, No.19, pp. 90649068, ISSN 0027-8424; 0027-8424

Pittenger, M.F. \& Martin, B.J. Mesenchymal stem cells and their potential as cardiac therapeutics. (2004). Circulation research, Vol.95, No.1, pp. 9-20, ISSN 1524-4571; 0009-7330

Place, E.S.; Evans, N.D. \& Stevens, M.M. Complexity in biomaterials for tissue engineering. (2009). Nature materials, Vol.8, No.6, pp. 457-470, ISSN 1476-1122; 1476-1122

Raeber, G.P.; Lutolf, M.P. \& Hubbell, J.A. Molecularly engineered PEG hydrogels: a novel model system for proteolytically mediated cell migration. (2005). Biophysical journal, Vol.89, No.2, pp. 1374-1388, ISSN 0006-3495; 0006-3495

Rexeisen, E.L.; Fan, W.; Pangburn, T.O.; Taribagil, R.R.; Bates, F.S.; Lodge, T.P.; Tsapatsis, M. \& Kokkoli, E. Self-Assembly of Fibronectin Mimetic Peptide-Amphiphile Nanofibers. (2010). Langmuir, Vol.26, No.3, pp. 1953-1959, ISSN 0743-7463

Richardson, T.P.; Peters, M.C.; Ennett, A.B. \& Mooney, D.J. Polymeric system for dual growth factor delivery. (2001). Nature biotechnology, Vol.19, No.11, pp. 1029-1034, ISSN 1087-0156; 1087-0156

Riddle, K.W. \& Mooney, D.J. Biomaterials for cell immobilisation. A look at carrier design. (2004). Vol.8A, No.1, pp. 1-19, ISSN 978-1-4020-1887-9

Rowley, J.A.; Madlambayan, G. \& Mooney, D.J. Alginate hydrogels as synthetic extracellular matrix materials. (1999). Biomaterials, Vol.20, No.1, pp. 45-53, ISSN 0142-9612; 01429612

Rowley, J.A. \& Mooney, D.J. Alginate type and RGD density control myoblast phenotype. (2002). Journal of Biomedical Materials Research, Vol.60, No.2, pp. 217-223, ISSN 00219304; 0021-9304

Rozario, T. \& DeSimone, D.W. The extracellular matrix in development and morphogenesis: a dynamic view. (2010). Developmental biology, Vol.341, No.1, pp. 126-140, ISSN 1095-564X; 0012-1606

Ruiz, S.A. \& Chen, C.S. Emergence of patterned stem cell differentiation within multicellular structures. (2008). Stem cells (Dayton, Ohio), Vol.26, No.11, pp. 2921-2927, ISSN 15494918; 1066-5099 
Ryadnov, M.G. \& Woolfson, D.N. Engineering the morphology of a self-assembling protein fibre. (2003). Nature materials, Vol.2, No.5, pp. 329-332, ISSN 1476-1122; 1476-1122

Salinas, C.N. \& Anseth, K.S. Mixed Mode Thiolâ^^Acrylate Photopolymerizations for the Synthesis of PEGâ^’Peptide Hydrogels. (2008). Macromolecules, Vol.41, No.16, pp. 6019-6026, ISSN 0024-9297

Sands, R.W. \& Mooney, D.J. Polymers to direct cell fate by controlling the microenvironment. (2007). Current opinion in biotechnology, Vol.18, No.5, pp. 448453, ISSN 0958-1669; 0958-1669

Sasisekharan, R.; Shriver, Z.; Venkataraman, G. \& Narayanasami, U. Roles of heparansulphate glycosaminoglycans in cancer. (2002). Nature reviews.Cancer, Vol.2, No.7, pp. 521-528, ISSN 1474-175X; 1474-175X

Shen, Y.H.; Shoichet, M.S. \& Radisic, M. Vascular endothelial growth factor immobilized in collagen scaffold promotes penetration and proliferation of endothelial cells. (2008). Acta biomaterialia, Vol.4, No.3, pp. 477-489, ISSN 1742-7061; 1742-7061

Shoichet, M.S. Polymer Scaffolds for Biomaterials Applications. (2010). Macromolecules, Vol.43, No.2, pp. 581-591, ISSN 0024-9297

Silva, G.A.; Czeisler, C.; Niece, K.L.; Beniash, E.; Harrington, D.A.; Kessler, J.A. \& Stupp, S.I. Selective differentiation of neural progenitor cells by high-epitope density nanofibers. (2004). Science (New York, N.Y.), Vol.303, No.5662, pp. 1352-1355, ISSN 1095-9203; 0036-8075

Stachowiak, A.?.; Bershteyn, A.; Tzatzalos, E. \& Irvine, D.?. Bioactive Hydrogels with an Ordered Cellular Structure Combine Interconnected Macroporosity and Robust Mechanical Properties. (2005). Advanced Materials, Vol.17, No.4, pp. 399-403, ISSN 1521-4095

Sun, Q.; Silva, E.A.; Wang, A.; Fritton, J.C.; Mooney, D.J.; Schaffler, M.B.; Grossman, P.M. \& Rajagopalan, S. Sustained release of multiple growth factors from injectable polymeric system as a novel therapeutic approach towards angiogenesis. (2010). Pharmaceutical research, Vol.27, No.2, pp. 264-271, ISSN 1573-904X; 0724-8741

Suzuki, T.; Yokoyama, Y.; Kumano, K.; Takanashi, M.; Kozuma, S.; Takato, T.; Nakahata, T.; Nishikawa, M.; Sakano, S.; Kurokawa, M.; Ogawa, S. \& Chiba, S. Highly efficient ex vivo expansion of human hematopoietic stem cells using Delta1-Fc chimeric protein. (2006). Stem cells (Dayton, Ohio), Vol.24, No.11, pp. 2456-2465, ISSN 10665099; 1066-5099

Tan, J.L.; Tien, J.; Pirone, D.M.; Gray, D.S.; Bhadriraju, K. \& Chen, C.S. Cells lying on a bed of microneedles: an approach to isolate mechanical force. (2003). Proceedings of the National Academy of Sciences of the United States of America, Vol.100, No.4, pp. 14841489, ISSN 0027-8424; 0027-8424

Tan, J.L.; Tien, J. \& Chen, C.S. Microcontact Printing of Proteins on Mixed Self-Assembled Monolayers. (2002). Langmuir, Vol.18, No.2, pp. 519-523, ISSN 0743-7463

Tanaka, H.; Murphy, C.L.; Murphy, C.; Kimura, M.; Kawai, S. \& Polak, J.M. Chondrogenic differentiation of murine embryonic stem cells: effects of culture conditions and dexamethasone. (2004). Journal of cellular biochemistry, Vol.93, No.3, pp. 454-462, ISSN 0730-2312; 0730-2312

Tayalia, P.; Mendonca, C.R.; Baldacchini, T.; Mooney, D.J. \& Mazur, E. 3D Cell-Migration Studies using Two-Photon Engineered Polymer Scaffolds. (2008). Advanced Materials, Vol.20, No.23, pp. 4494-4498, ISSN 1521-4095 
Tibbitt, M.W. \& Anseth, K.S. Hydrogels as extracellular matrix mimics for 3D cell culture. (2009). Biotechnology and bioengineering, Vol.103, No.4, pp. 655-663, ISSN 1097-0290; 0006-3592

Tsang, K.Y.; Cheung, M.C.; Chan, D. \& Cheah, K.S. The developmental roles of the extracellular matrix: beyond structure to regulation. (2010). Cell and tissue research, Vol.339, No.1, pp. 93-110, ISSN 1432-0878; 0302-766X

Watt, F.M.; Jordan, P.W. \& O'Neill, C.H. Cell shape controls terminal differentiation of human epidermal keratinocytes. (1988). Proceedings of the National Academy of Sciences of the United States of America, Vol.85, No.15, pp. 5576-5580, ISSN 0027-8424; 0027-8424

Whitesides, G.M. The origins and the future of microfluidics. (2006). Nature, Vol.442, No.7101, pp. 368-373, ISSN 1476-4687; 0028-0836

Willerth, S.M.; Johnson, P.J.; Maxwell, D.J.; Parsons, S.R.; Doukas, M.E. \& Sakiyama-Elbert, S.E. Rationally designed peptides for controlled release of nerve growth factor from fibrin matrices. (2007). Journal of biomedical materials research.Part A, Vol.80, No.1, pp. 13-23, ISSN 1549-3296; 1549-3296

Wong Po Foo, C.; Patwardhan, S.V.; Belton, D.J.; Kitchel, B.; Anastasiades, D.; Huang, J.; Naik, R.R.; Perry, C.C. \& Kaplan, D.L. Novel nanocomposites from spider silk-silica fusion (chimeric) proteins. (2006). Proceedings of the National Academy of Sciences of the United States of America, Vol.103, No.25, pp. 9428-9433, ISSN 0027-8424; 00278424

Wosnick, J.H. \& Shoichet, M.S. Three-dimensional Chemical Patterning of Transparent Hydrogels. (2008). Chemistry of Materials, Vol.20, No.1, pp. 55-60, ISSN 0897-4756

Xin, X.; Borzacchiello, A.; Netti, P.A.; Ambrosio, L. \& Nicolais, L. Hyaluronic-acid-based semi-interpenetrating materials. (2004). Journal of biomaterials science.Polymer edition, Vol.15, No.9, pp. 1223-1236, ISSN 0920-5063; 0920-5063

Yamada, K.M. \& Cukierman, E. Modeling tissue morphogenesis and cancer in 3D. (2007). Cell, Vol.130, No.4, pp. 601-610, ISSN 0092-8674; 0092-8674

Yamaguchi, N. \& Kiick, K.L. Polysaccharide-poly(ethylene glycol) star copolymer as a scaffold for the production of bioactive hydrogels. (2005). Biomacromolecules, Vol.6, No.4, pp. 1921-1930, ISSN 1525-7797; 1525-7797

Zhang, S. Fabrication of novel biomaterials through molecular self-assembly. (2003). Nature biotechnology, Vol.21, No.10, pp. 1171-1178, ISSN 1087-0156; 1087-0156

Zhou, X.; Rowe, R.G.; Hiraoka, N.; George, J.P.; Wirtz, D.; Mosher, D.F.; Virtanen, I.; Chernousov, M.A. \& Weiss, S.J. Fibronectin fibrillogenesis regulates threedimensional neovessel formation. (2008). Genes $\mathcal{E}$ development, Vol.22, No.9, pp. 1231-1243, ISSN 0890-9369; 0890-9369 


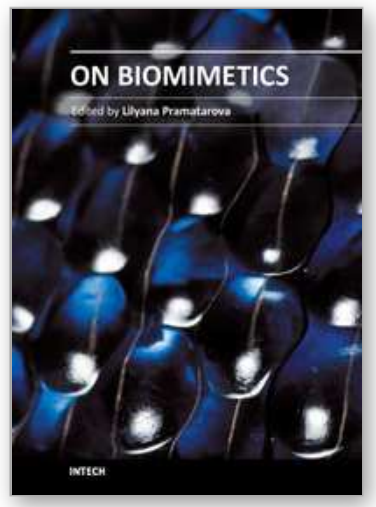

\author{
On Biomimetics \\ Edited by Dr. Lilyana Pramatarova
}

ISBN 978-953-307-271-5

Hard cover, 642 pages

Publisher InTech

Published online 29, August, 2011

Published in print edition August, 2011

Bio-mimicry is fundamental idea â€ How to mimic the Natureâ€TM by various methodologies as well as new ideas or suggestions on the creation of novel materials and functions. This book comprises seven sections on various perspectives of bio-mimicry in our life; Section 1 gives an overview of modeling of biomimetic materials; Section 2 presents a processing and design of biomaterials; Section 3 presents various aspects of design and application of biomimetic polymers and composites are discussed; Section 4 presents a general characterization of biomaterials; Section 5 proposes new examples for biomimetic systems; Section 6 summarizes chapters, concerning cells behavior through mimicry; Section 7 presents various applications of biomimetic materials are presented. Aimed at physicists, chemists and biologists interested in biomineralization, biochemistry, kinetics, solution chemistry. This book is also relevant to engineers and doctors interested in research and construction of biomimetic systems.

\title{
How to reference
}

In order to correctly reference this scholarly work, feel free to copy and paste the following:

Edorta Santos, Gorka Orive, Rosa M Hernández and Jose Luis Pedraz (2011). Cell-Biomaterial Interaction: Strategies To Mimic The Extracellular Matrix, On Biomimetics, Dr. Lilyana Pramatarova (Ed.), ISBN: 978-953307-271-5, InTech, Available from: http://www.intechopen.com/books/on-biomimetics/cell-biomaterialinteraction-strategies-to-mimic-the-extracellular-matrix

\section{INTECH}

open science | open minds

\section{InTech Europe}

University Campus STeP Ri

Slavka Krautzeka 83/A

51000 Rijeka, Croatia

Phone: +385 (51) 770447

Fax: +385 (51) 686166

www.intechopen.com

\section{InTech China}

Unit 405, Office Block, Hotel Equatorial Shanghai No.65, Yan An Road (West), Shanghai, 200040, China 中国上海市延安西路65号上海国际贵都大饭店办公楼 405 单元 Phone: +86-21-62489820

Fax: $+86-21-62489821$ 
(C) 2011 The Author(s). Licensee IntechOpen. This chapter is distributed under the terms of the Creative Commons Attribution-NonCommercialShareAlike-3.0 License, which permits use, distribution and reproduction for non-commercial purposes, provided the original is properly cited and derivative works building on this content are distributed under the same license. 